\title{
Fracture Behaviour of Rubber- and Silica Nanoparticle-Toughened Glass Fibre Composites under
} Static and Fatigue Loading

Shamsiah $\underline{\text { wang Ngah }}^{1,2}$, Ambrose C. Taylor $^{1 *}$

1. Department of Mechanical Engineering, Imperial College London, South Kensington Campus, London SW7 2AZ, UK.

2. Present address: Department of Architecture and Civil Engineering, University of Bath, Bath BA2 7AY, UK. ${ }^{*}$ Corresponding author: Email: a.c.taylor@imperial.ac.uk $\quad$ Tel: +44 2075947149

\begin{abstract}
The crosslinked polymers used in fibre composites are very brittle, and require toughening for structural applications. Research over many years has increased the fracture energy, but the fatigue resistance of these toughened polymers is very poor, limiting the optimisation of structures. This work reports the first successful use of hybrid toughening to increase both the quasi-static interlaminar fracture energy, $\mathrm{G}_{\mathrm{C}}$, and the fatigue threshold strain-energy release-rate, $\mathrm{G}_{\mathrm{th}}$. Aminecured epoxy glass-fibre composites were toughened using carboxyl-terminated butadieneacrylonitrile (CTBN) which forms micron-sized rubber particles and $20 \mathrm{~nm}$-diameter silica nanoparticles. The toughening mechanisms were identified as cavitation of rubber particles and debonding for the silica nanoparticles, followed by plastic void growth. The CTBN greatly increases $\mathrm{G}_{\mathrm{IC}}$, and the nanoparticles increase $\mathrm{G}_{\mathrm{th}}$. Combining both particles as a hybrid has a synergistic effect on the fatigue resistance. This demonstrates the effectiveness of hybrid toughening, enabling the design of optimised composites by combining micro- and nanoparticles.
\end{abstract}

Keywords:

A: Glass Fibres; A: Nanoparticles; B: Fatigue; B: Fracture

\section{Introduction}

Epoxy polymers can be used as adhesives, coatings or as the matrices of fibre-reinforced composite materials. They are highly crosslinked thermosetting polymers, and this structure results 
in high modulus, high strength, good performance at temperatures below the glass transition temperature and low creep. However, they are very brittle due to this highly cross-linked structure which leads to a poor resistance to crack initiation and propagation, under both quasi-static and fatigue loading.

When used as a structural material, such as the matrix for fibre composites, epoxy polymers require toughening to prevent the growth of the inevitable defects which are present in the materials and subsequent failure. It is difficult to detect cracks in composite structures, and hence preventing crack growth by increasing the material's toughness under both quasi-static and fatigue loading is preferred to monitoring crack growth as can be done with metal structures.

Various approaches have been used to toughen epoxy polymers, which can include the addition of rubbers [1-5], thermoplastics [6, 7], ceramic particles [8, 9], glass microparticles [10-14] or silica nanoparticles [15]. Among these, the most successful approach has been the addition of rubber modifiers such as carboxyl-terminated butadiene acrylonitrile (CTBN) which phase-separate into micron-sized particles during curing of the epoxy polymer [16]. Recent advances have seen the use of different forms of rubber modifiers such as block co-poplymers [17-19] and core-shell rubber (CSR) nanoparticles [20-22] to increase the toughness of epoxy polymers. This is because these modifiers have been shown to improve toughness above $10 \mathrm{wt} \%$ loading whereas the toughening of micron-sized rubber particles tends to remain constant or decline above $10 \mathrm{wt} \%$ [23].

Combinations of two different types of particles, combining soft and rigid particles in the same formulation have also been used [5, 24-28]. All these studies have reported significant increases in the toughness of the bulk polymers and their corresponding fibre reinforced composites tested under static loading. Both CTBN and CSR particles have been used, often combined with silica nanoparticles. In some cases the combination of soft and rigid particles gave an additional (synergistic) toughening effect, but in other cases there was little increase in toughness due to the addition of the second particle type.

Blackman et al. [29] and Manjunatha et al. [30, 31] extended the study of toughening using these particles to fatigue loading. They found that the fatigue threshold strain energy release rate, below which a crack does not grow and which is an important criterion for design, increased significantly. The fatigue life of the materials was also increased. Other researchers have used 
other nanoscale fillers such as carbon nanotubes (CNTs) [32], carbon nanofibres (CNFs) [33] and nanoclay particles [34] to improve the fatigue performance of bulk polymers. These studies have clearly demonstrated that a remarkable increase in the fatigue threshold and a significant reduction in the fatigue crack growth rate can be achieved with the addition of only small weight fractions of these nanoparticles.

Most studies have focussed on improving the fatigue performance of bulk epoxy polymers, whereas few studies can be found in the literature on the fatigue behaviour of toughened fibre reinforced composites. Manjunatha et al. [31] studied the tensile-fatigue behaviour of glass fibre composites similar to the ones being manufactured in the present work, and presented the stress versus lifetime (S-N) curves. Their results corroborate the previous findings that the use of toughened epoxies as the matrices in GF composites is beneficial in enhancing the fatigue life of composite structures. Work by Boger et al. [35] supported these results, demonstrating an increase of up to $16 \%$ in the inter fibre fracture strength as well as an increase in the high cycle fatigue life of several orders of magnitude.

The fatigue performance of fibre reinforced composites has also been shown to improve remarkably by using CNT and CNF modified matrices when subjected to tension-tension fatigue loading [36, 37]. Kostopoulos et al. [36] investigated CF composite structures where CNTs acted as matrix reinforcement as well as electrical sensors for damage monitoring, concluding that the large surface area and aspect ratio of CNTs contributed to prolonging the fatigue life. Zhou et al. [37] investigated vapour grown CNF modified matrices in CF composites, observing the highest fatigue life and the maximum fatigue strength coefficient, $\sigma_{f}$, with the addition of $2 \mathrm{wt} \% \mathrm{CNF}$. However, both parameters declined with higher CNF concentrations.

The fatigue behaviours of composites in the above studies have been discussed in terms of fatigue life and strength by plotting the S-N curves from tension-tension fatigue loading. There have been very limited studies on the effect of similar matrix modifications on the fatigue threshold and fatigue crack growth (FCG) rate in composite structures. These are measured using mode I interlaminar fracture tests under cyclic loading. Publications which report the mode I fatigue behaviour subjected are for bonded composites $[38,39]$ or the through-thickness toughened composites using interleaf [40, 41], z-anchor [42], or z-pinning [43]. Nonetheless, Grimmer and 
Dharan [44] have looked at the effect of CNT matrix modification and observed a significant reduction of FCG rate as well as an increase in the fatigue threshold for composite specimens containing CNTs.

This work reports, for the first time, the fatigue fracture performance of fibre composites toughened with carboxyl-terminated butadiene-acrylonitrile (CTBN) and $20 \mathrm{~nm}$ diameter silica nanoparticles. The matrix contribution towards the fracture energy for GF composites under static and fatigue loading are discussed. The effect of crosslink density is investigated. In addition, the toughening mechanisms for the composites are examined to study the relationship between the fatigue and static fracture behaviour, the type of crack growth and detailed features of the associated fracture surfaces. This shows how the composite toughness can be increased under both quasi-static and fatigue loading by combining micron-sized CTBN particles and nanometresized silica particles. Use of these materials can give composite structures which are more tolerant of defects, leading to safer and lighter weight structures.

\section{Experimental}

\subsection{Materials}

An amine-cured epoxy was used due to its low viscosity and long pot life which makes it suitable for resin transfer moulding and resin infusion [45]. The epoxy resin was a diglycidyl ether of bisphenol F (DGEBF), Epikote 862 supplied by Hexion Specialty Chemicals, UK, with an epoxide equivalent weight (EEW) of $169 \mathrm{~g} / \mathrm{eq}$ [45]. The curing agent was Epikure $\mathrm{W}$, an aromatic diamine with an hydrogen equivalent weight (HEW) of $45 \mathrm{~g} / \mathrm{eq}$ from the same manufacturer. A mixing ratio of $100: 26.4$ by weight was used.

The glass fibre reinforcement used was a biaxial $\pm 45^{\circ}$ double layer non-crimp fabric (NCF) with an areal weight of $450 \mathrm{~g} / \mathrm{m}^{2}$ from SP Systems, UK. Non-crimp fabric reinforcement was chosen due to its mechanical and manufacturing benefits. The resulting composites exhibit higher in-plane properties and superior delamination resistance and damage tolerance in comparison to conventional woven reinforcement due to the absence of crimp in the fibre architecture [46].

The rubber adduct used was a low molecular weight carboxyl-terminated butadieneacrylonitrile (CTBN) copolymer, Albipox 1000 from Evonik, Germany. Albipox 1000 contains 40 
$w t \%$ of nitrile rubber in a DGEBA epoxy resin with $18 \%$ acrylonitrile content. The silica nanoparticles (NS) used were Nanopox F400 from Evonik, Germany, and were supplied as a masterbatch containing $40 \mathrm{wt} \%$ of silica $\left(\mathrm{SiO}_{2}\right)$ dispersed in DGEBA epoxy resin as a colloidal mixture. The particles were supplied surface-modified using a silane [47] to prevent agglomeration, and have a narrow particle size distribution with an average diameter of $20 \mathrm{~nm}$ [48].

\subsection{Manufacturing of GF Composites}

A thick and stiff laminate is required to avoid large deflections of the composite arms during mode I fracture tests. The glass fibre (GF) composite laminates, $300 \mathrm{~mm} \times 300 \mathrm{~mm}$ in size with an average thickness of $5 \mathrm{~mm}$ were prepared by infusing modified epoxy formulations into 16 layers of glass fibre preforms, using resin infusion under flexible tooling (RIFT). The fabrics were arranged as a quasi-isotropic lay-up of $\left[(-45 /+45)_{s} /(90 / 0)_{s}\right]_{2} /$ film insert/[(0/90) $\left.)_{s}(+45 /-45)_{s}\right]_{2}$ to give a $0^{\circ} / 90^{\circ}$ ply interface at the midplane in order to minimise the fibre bridging effect, allowing a better evaluation of the matrix toughness contribution. As composite laminates exhibit deformation coupling behaviour between in-plane and out-of-plane response due to stacking (layering) of fibre reinforcement in various orientation, this lay-up also minimises the elastic membrane-bending and bend-twist coupling effect (i.e. laminate stiffness characteristic, the A-B-D matrix) which can result in highly curved delamination fronts and lead to overestimation of the fracture energy [49].

The lay-up configuration used caused the laminate to be unsymmetrical but balanced. However, stress analysis has shown that the bend-twist coupling effect is negligible. The firm insert was a strip of non-perforated, $25 \mu \mathrm{m}$ thick fluorinated ethylene propylene (FEP) release film which was placed into the centre of the $330 \mathrm{~mm} \times 330 \mathrm{~mm}$ panel. This created a $45-55 \mathrm{~mm}$ long starter crack for the double cantilever beam specimens.

The epoxy formulations were prepared by stirring the CTBN and NS masterbatches into the epoxy resin to give $9 \mathrm{wt} \%$ rubber and $10 \mathrm{wt} \% \mathrm{NS}$. The measured density of the cured epoxy was $1190 \mathrm{~kg} / \mathrm{m}^{3}$ [50]. The CTBN particles have a density of $948 \mathrm{~kg} / \mathrm{m}^{3}$, and the silica nanoparticles of $1800 \mathrm{~kg} / \mathrm{m}^{3}$ [51]. Thus these weight percentages are equivalent to $11 \mathrm{vol} \%$ rubber and $6.8 \mathrm{vol} \%$ NS respectively. A control GF composite with an unmodified epoxy matrix was also manufactured. An overhead stirrer, RZR from Heidolph, Germany, fitted with a bladed impeller, was used to mix the formulations. The curing agent was added stoichiometrically, and the mixture was stirred again. 
The mixture was degassed prior to infusion to remove any air bubbles resulting from the stirring process.

Once the infusion process was complete, the laminates were cured using one of two different cure schedules (i) 2 hrs at $100^{\circ} \mathrm{C}$ and 10 hours at $180^{\circ} \mathrm{C}$, and (ii) 2 hrs at $80^{\circ} \mathrm{C}$ and 8 hours at $120^{\circ} \mathrm{C}$. This was to analyse the effect of matrix crosslink density on the composite toughness.

\subsection{Thermal Analysis - Glass Transition Temperature and Crosslink Density}

Dynamic mechanical analysis (DMA) was used to measure the glass transition temperature, $T_{g}$, of the composites and to determine the matrix crosslink density, $M_{c}$. A Q800 DMA from TA Instruments was used. The thickness of the composite laminate was reduced to approximately 2.5 $-3.0 \mathrm{~mm}$ by grinding to reduce the sample stiffness. A $60 \mathrm{~mm} \times 10 \mathrm{~mm}$ specimen was mounted in a dual cantilever fixture and tested in bending using strain control. A frequency of $1 \mathrm{~Hz}$ was used, over a temperature range of $-80{ }^{\circ} \mathrm{C}$ to $200{ }^{\circ} \mathrm{C}$ using a ramp rate of $2{ }^{\circ} \mathrm{C} / \mathrm{min}$. The $\mathrm{T}_{\mathrm{g}}$ can be defined by a large drop of storage modulus curve, known as $T_{g}$ Onset, or the peak of the tan $\delta$ curve, known as $T_{g}$ Peak. In this work, both $T_{g}$ values are reported, but $T_{g}$ Peak will be referred to in the discussion.

DMA was also performed on bulk polymer samples. The rubbery equilibrium storage modulus, $E_{R}$, can be used to determine the matrix crosslink density, $M_{c}$, using an empirical formula [52],

$$
\log \frac{E_{R}}{3}=6+\frac{293 \rho}{M_{c}} \quad \text { Equation } 1
$$

where $M_{c}$ is the number average molecular weight between crosslinks in $\mathrm{g} / \mathrm{mol}, E_{R}$ is the equilibrium modulus in the rubbery region taken at $\mathrm{T}_{\mathrm{g}}+50^{\circ} \mathrm{C}$ in $\mathrm{Pa}$, and $\rho$ is the density of the epoxy in $\mathrm{g} / \mathrm{cm}^{3}$.

\subsection{Mode I Interlaminar Fracture Test}

Quasi-static mode I interlaminar fracture tests were carried out in accordance with ASTM D5528 [53] and BS EN ISO 15024 [54]. Double cantilever beam (DCB) specimens, of $150 \mathrm{~mm} \times 20$ $\mathrm{mm}$ were cut from the 5-mm-thick composite plates. The ends of the DCBs containing the starterfilm were gritblasted and acetone-wiped, and aluminium endblocks were bonded on using a twocomponent epoxy paste adhesive, Araldite 2011 from Huntsman, UK. The adhesive was cured at room temperature overnight. 
At least three specimens were tested for each formulation. The DCBs were tested at a loading rate of $1 \mathrm{~mm} / \mathrm{min}$ using an Instron 5584 universal testing machine with a $5 \mathrm{kN}$ load cell. The specimen was loaded in two stages. The initial loading (pre-cracking) generated a natural crack approximately $10 \mathrm{~mm}$ beyond the film insert. The specimen was unloaded, and then reloaded until the crack propagated another $70-80 \mathrm{~mm}$. Load versus displacement curves were recorded, and the crack growth was monitored using a travelling microscope. The specimen was then unloaded, and subsequently broken open to allow the fracture surfaces to be imaged.

The fracture energy, $G_{\mathbb{I C}}$, was calculated via the modified beam theory (MBT) method [55] using

$$
\boldsymbol{G}_{I C}=\frac{3 P(\delta / N) F}{2 B(a+\Delta)} \quad \text { Equation } 2
$$

where $P$ is the applied load, $\delta$ is the displacement, and $B$ is the specimen width. The endblock correction factor, $\mathrm{N}$, and the large displacement correction factor, $\mathrm{F}$, were calculated as per the Standard [54]. The crack length correction factor, $\Delta$, was determined experimentally by plotting $(\mathrm{C} / \mathrm{N})^{1 / 3}$ as a function of crack length, where $\mathrm{C}$ is the compliance. The resulting straight line intersects the crack length axis at $-\Delta$, and a value of $\Delta=0$ was used if a positive intercept was obtained, as specified by the British Standard [54].

The initiation value for $\mathrm{G}_{\mathrm{C}}$ was determined using three approaches, i.e. visual observation (VIS), deviation from non-linearity (NL) and the $5 \%$ offset or maximum load during the test (i.e. after pre-cracking) [54]. The $G_{I C}$ initiation ( $\left.G_{\mid C, \text { Init }}\right)$ value quoted is the non-linear value, as accurate determination of the value from visual observation is always difficult and operator dependent. The propagation value of the fracture energy $\left(\mathrm{G}_{\mathrm{IC}, \text { Prop }}\right)$ was calculated by averaging the values in the plateau region after the initiation point.

The laminates were laid up with a $0 \% 190^{\circ}$ ply interface at the midplane to minimise the fibre bridging effect, allowing a better evaluation of the matrix toughness contribution. For interface cracks of dissimilar ply orientations $\left(0^{\circ} / \theta^{\circ}\right)$, it is known that mixed mode failure exists due to the oscillatory nature of the stresses and displacements near the crack tip [56, 57]. Although the calculation of the total strain energy release rate, $G$, is well established, it is not possible to calculate the individual strain energy release rate components, $G_{\mid}, G_{\|}$and $G_{\| I}$, at the interface. 
Qian and Sun [56] proposed the use of finite extension strain energy release rates to overcome this ambiguity for bimaterial interface cracks. Here the finite crack extension, $\Delta a$, should be equal to a characteristic damage zone length, $I_{c}$, of the order of the layer thickness, as the solutions do not converge as $\Delta$ a approaches zero due to the oscillations. However, another study [57] has shown that the modified beam theory (MBT) data reduction, as used in the present work, is accurate for multidirectional specimens and MBT has been used successfully to analyse fractures in many recent interlaminar fracture studies, e.g. [58-62].

\subsection{Fatigue Crack Growth (FCG)}

Fatigue crack growth tests were carried out for all of the $180^{\circ} \mathrm{C}$ cured GF composites using DCB specimens on an Instron 8872 servohydraulic universal testing machine fitted with a $1 \mathrm{kN}$ load cell. The test was not carried out in accordance with any specific standards, instead it refers to ASTM E647 [63] and BS ISO 13003 [64] as guidelines. The specimens were not pre-cracked and therefore the fibre bridging effect on the crack initiation was negligible. The composite specimens were prepared from the same composite laminate as was used for the fracture tests.

The DCB specimens were loaded in displacement control under sinusoidal loading at a frequency of $3 \mathrm{~Hz}$ with a displacement ratio, $\mathrm{R}=\left(\frac{\partial_{\min }}{\partial_{\max }}\right)$, of 0.1 . This frequency is sufficiently low to prevent heating of the composite. The maximum displacement was set at $75 \%$ of the displacement required for crack initiation in the corresponding quasi-static test. The amplitude used varied from 3.7 to $9.5 \mathrm{~mm}$ depending on the matrix formulation, the specimen thickness and the initial crack length.

Load, displacement and crack length data were recorded at specified intervals depending on the crack propagation rate; more frequently in the early stages and less frequently when the crack growth rate slowed down. The test was stopped when no further crack propagation was observed and there was no decrease in the maximum load after a period of time, i.e. after approximately 9 million cycles.

\subsubsection{Data Reduction}

The fatigue data are characterised by plotting the rate at which the crack propagates per cycle $(\mathrm{da} / \mathrm{dN})$ versus the maximum applied strain energy release rate $\mathrm{G}_{1}$ Max. The value of $\mathrm{G}_{\mathrm{I} \text { Max }}$ 
was determined using Equation 2; $G_{1}$ Max is used rather than $\Delta G$ (where $\Delta G=G_{1 \operatorname{Max}}-G_{1 \text { Min }}$ ), as facial interference on unloading artificially raises the minimum applied strain energy release rate $G_{1}$ Min and reduces the $\Delta G$ value [38]. The fatigue crack growth rate $(\mathrm{da} / \mathrm{dN})$ was calculated using the incremental polynomial method, by fitting a second-order polynomial to sets of $(2 n+1)$ successive data points to reduce scatter in the experimental data. A 7-point polynomial is used $(n=3)$ so the polynomial is fitted to successive sets of 7 data points [63]. This method has gained wide acceptance as the preferred crack growth rate calculation method [65]. The fitted second order polynomial equation is given by

$$
\frac{d a}{d N}=\frac{b_{1}}{C_{2}}+2 b_{2}\left[\frac{N_{\mathrm{i}}-C_{1}}{C_{2}^{2}}\right]
$$

where $N_{\mathrm{i}}$ is the $i$ th cycle, $b_{1}$ and $b_{2}$ are regression parameters which are determined by applying the method of least squares to the data, while $C_{1}$ and $C_{2}$ are parameters used to scale the input data to avoid numerical difficulties when determining the regression parameters [63].

\subsubsection{Fatigue Crack Growth (FCG) Plot}

The relationship between the rate at which the fatigue crack propagates per cycle, da/dN, and the maximum strain energy release rate, $G_{1 \text { Max }}$, is a sigmoidal curve, see Figure 1 . The FCG plot can be divided into three regions as shown in Figure 1. Region III is normally associated with fast fracture and unstable crack growth as $G_{I M a x}$ approaches the $G_{I C}$ value for the composite from the quasi-static test. Region II shows a linear crack growth region which fits the Paris law relationship,

$$
\log \left(\frac{d a}{d N}\right)=m \log \left(G_{I \text { Max }}\right)+\log C
$$

Equation 4

where $\mathrm{da} / \mathrm{dN}$ is the rate of crack growth per cycle, $\mathrm{G}_{\mathrm{IMax}}$ is the maximum strain energy release rate in a cycle, $m$ is the Paris law coefficient and $C$ is a material constant.

Region I is the slow crack growth region where $G_{I M a x}$ approaches the threshold value, $G_{t h}$, below which no significant crack growth occurs. At this stage the crack growth is dormant or growing at an undetectable rate [38]. The threshold strain energy release rate, $\mathrm{G}_{\mathrm{th}}$, is taken at the pronounced knee of the plot and the gradient of the Paris-law region, $m$, is computed from Equation 4. 
The Paris-law region is associated with fatigue crack propagation and the parameter $m$ indicates the load sensitivity of the crack propagation rate. The value of $m$ in adhesives and composite materials is much greater than in metals, so the fatigue threshold value is preferred as a design consideration [38], as once a crack is growing it will reach a critical size very quickly, therefore it is best to design for no crack growth.

\subsection{Microscopy Analysis}

Fractography of the fracture surfaces was carried out using an Hitachi S-3400N scanning electron microscope (SEM), and a Leo Gemini 1525 field emission gun SEM (FEGSEM). Typical accelerating voltages of $15 \mathrm{kV}$ and $5 \mathrm{kV}$ were used for SEM and FEGSEM imaging respectively, with a working distance of $5-10 \mathrm{~mm}$. The specimens were attached to aluminium stubs using selfadhesive conductive tape. A fine stripe of silver paint was also painted on one end of the specimen to act as a discharge bridge. The specimens were then sputter-coated with an ultra-thin layer of gold (SEM) or chromium (FEGSEM) to prevent charging and give better resolution.

\section{Results and Discussion}

\subsection{Introduction}

The results of the dynamic mechanical analysis are presented first, considering the effect of the two different cure cycles and the addition of particles on the glass transition temperature of the epoxy matrix. The results obtained from the fracture tests are divided into two sections, firstly the quasi-static mode I fracture and secondly the fatigue fracture results. The quasi-static analysis considers the effect on the rubber and silica particle toughening from the two different curing temperatures to demonstrate the effect of varying crosslink density on the toughness. The fatigue fracture data present the results from a single curing temperature, to identify the differences between quasi-static and fatigue performance. The fracture morphology and the toughening mechanisms of the composites are identified from electron micrographs for both quasi-static and fatigue fracture, to understand the correlation between the measured fracture energy, the type of crack growth and detailed features on the associated fracture surfaces. 


\subsection{Glass Transition Temperature, $\mathrm{T}_{\mathrm{g}}$}

Typical dynamic mechanical analysis results for the GF composites for both curing temperatures are shown in Figure 2, and show the measured values of $T_{g}$ Onset and $T_{g}$ Peak. The main peak in the tan $\delta$ response in Figure 2 is the $T_{g}$ of the epoxy matrix. Figure 2 (a) and (c) show only a single peak from the epoxy matrix. Figure 2 (b) and (d) show the GF-Rubber and GF-Hybrid composites, where the second, smaller, peak represents the $T_{g}$ for the rubber that has phaseseparated. The measured values of -40 to $-51^{\circ} \mathrm{C}$ agree well with the $-50^{\circ} \mathrm{C}$ reported by Wise et al. [66] and Hsieh et al. [26] for the $T_{g}$ of the rubber.

The $T_{g}$ values for the GF composites cured at $120^{\circ} \mathrm{C}$ and $180^{\circ} \mathrm{C}$ are shown in Table 1 . The $T_{g}$ Peak values for the corresponding bulk matrix samples [50] are also presented in Table 1 . The bulk polymer values are similar to the GF composite data, and exhibit the same trends as expected because $T_{g}$ is a matrix-dominated property. The $T_{g}$ values for the formulations cured at $120^{\circ} \mathrm{C}$ are lower than those cured at $180^{\circ} \mathrm{C}, \mathrm{T}_{\mathrm{g}}$ Peak values of $116{ }^{\circ} \mathrm{C}$ and $154{ }^{\circ} \mathrm{C}$ respectively being measured for the GF-Control samples, see Figure 2(a). The $\mathrm{T}_{\mathrm{g}}$ value for the $180{ }^{\circ} \mathrm{C}$ cure agrees well with values in the literature at the same cure temperature, e.g. $153^{\circ} \mathrm{C}$ measured by Hussain et al. [67] and $156{ }^{\circ} \mathrm{C}$ by Okoro et al. [68]. The $T_{g}$ Onset values follow the same trend as the $T_{g}$ Peak values, with $T_{g}$ Onset being about $10 \%$ lower than $T_{g}$ Peak.

Similar to the work of Hsieh et al. [26], the $T_{g}$ values for the GF-Rubber are lower than the GF-Control as some of the CTBN rubber has remained dissolved in the epoxy due to incomplete phase separation during curing, plasticising the matrix and hence reducing its $T_{g}$. The Fox equation [69] may be used to determine the amount of rubber remaining dissolved in the epoxy using

$$
\frac{1}{T_{g \text { MIX }}}=\frac{W_{\text {CTBN }}}{T_{g \text { CTBN }}}+\frac{W_{\text {Epoxy }}}{T_{g \text { Epoxy }}} \quad \text { Equation } 5
$$

where $T_{g \text { MIX }}$ is the glass transition temperature of the polymer mixture, $W_{\text {Epoxy }}$ and $W_{\text {CTBN }}$ are the weight fractions of the epoxy and CTBN respectively, and $T_{g}$ Epoxy and $T_{g}$ CTBN are the glass transition temperatures of the epoxy and CTBN respectively. Using the equation and the $T_{g}$ Peak values above, it was calculated that 1.8 vol\% of rubber did not phase separate in the GF-Rubber cured at $180{ }^{\circ} \mathrm{C}$, as a $6{ }^{\circ} \mathrm{C}$ drop in $T_{g}$ Epoxy was measured. There was no reduction in the $T_{g}$ value 
for the GF-Rubber cured at $120^{\circ} \mathrm{C}$ and this suggests that all the rubber in the resin mixture had undergone phase separation to form particles.

For the GF-NS, there was no significant increase in the $T_{g}$ values with the $120{ }^{\circ} \mathrm{C}$ cured formulation. Although the $180{ }^{\circ} \mathrm{C}$ data do show a small increase, see Figure 2 (b) and Table 1 , this is not significant. The addition of silica nanoparticles does not affect the polymer chain mobility, and hence no change in the $T_{g}$ would be expected $[8,9]$. In the case of GF-Hybrid, there was no significant difference between the GF-NS and GF-Hybrid $T_{g}$ values, despite the addition of CTBN. The absence of a reduction in the $T_{g}$ value shows that complete phase separation of the rubber has occurred in the GF-Hybrid.

\subsection{Quasi-static Fracture}

In the DCB tests, all the composites exhibited mainly unstable fracture with 'stick-slip' crack growth [70] during the early propagation stage. This gradually changed to a more stable crack growth with increasing crack length. The stick-slip behaviour was more pronounced in the GFRubber and GF-Hybrid composites. Stick-slip behaviour is generally observed in stitched fabric laminates, corresponding to a load drop as a result of stitch breakage during crack growth [71].

Typical R-curves for the GF composites at both curing conditions are shown in Figure 3. The

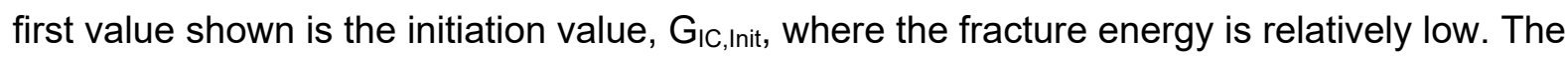
fracture energy increases rapidly with increasing crack length until it reaches a plateau, indicating that the steady state crack propagation region has been reached. The propagation value, $\mathrm{G}_{\mathrm{IC}, \text { Prop, }}$ is defined as the mean value for this plateau region. The fracture energy values for crack initiation and propagation are summarised in Table 2. The fracture energy values, $G_{c}$ Bulk for the corresponding bulk polymers [50] are also presented in Table 2 for comparison.

Two distinct R-curve behaviours can be observed in Figure 3 for the GF composites. The GF-Control and GF-NS generally showed relatively flat R-curve behaviour which suggests stable crack growth in which there is no change in the fracture mechanisms. On the other hand, the GFRubber and GF-Hybrid showed rising R-curves with some fluctuations, and these correspond well with the pronounced stick-slip behaviour previously mentioned. This phenomenon could be associated with periodic transverse cracking of the $90^{\circ}$ mid-layer and crack jumping between two neighbouring $0^{\circ} / 90^{\circ}$ ply interfaces [62]. It has also been generally observed that strong fibre-matrix 
interfacial adhesion favours unstable crack propagation while weak interfacial adhesion results in stable crack behaviour [72]. Hence, transverse cracking and crack jumping are less dominant in GF-Control and GF-NS providing less resistance to crack propagation and hence smaller Rcurves.

The GF composites cured at $120^{\circ} \mathrm{C}$ showed much higher fracture energies than those cured at $180^{\circ} \mathrm{C}$, so the samples show a greater toughness when cured at a relatively lower temperature. The use of a rubber-modified matrix at both curing temperatures increased significantly the fracture energies of the GF composites at initiation and propagation when compared to GF-Control, see Table 2. In contrast, the use of the NS-modified matrix gave only a small increase, or reduced the measured fracture energy. Only a marginal increase in the $G_{1 C}$ propagation value for GF-NS cured at $120^{\circ} \mathrm{C}$ was observed. Analysing the results for GF-Hybrid, the fracture energies were found to be in a similar range to those of GF-Rubber which suggests that the fracture energy increase was contributed by the rubber only and there was little contribution from the silica nanoparticles. Hence, it can be concluded that a synergistic toughening effect did not occur in the hybrid samples for quasi-static fracture.

\subsection{Quasi-static Fracture Surfaces and Toughening Mechanisms}

The images of the fracture surfaces of the quasi-static specimens are taken from the propagation region, and these are representative of both curing conditions unless otherwise specified. In all the composite samples, the crack initiated in the midplane at the $0^{\circ} / 90^{\circ}$ ply interfaces and propagated along the specimen. This involved matrix fracture, fibre debonding and pull-out in both the longitudinal and transverse directions. It was observed that the crack did not remain in the same plane but branched out into neighbouring plies resulting in stepped fracture surfaces, which is often seen in laminates with 0/0 interfaces [58, 72]. In GF-Rubber and GFHybrid, crack branching also led to multiple delaminations, and the multiple cracks formed are partly responsible for their higher fracture energies and hence larger R-curves..

The fracture for the GF-Control was dominated by a combination of matrix fracture, weak fibre-matrix interfacial adhesion and stitch breakage failure. The unmodified epoxy has a low matrix toughness due to its highly crosslinked nature. This is evident from the formation of scarps and riverlines as shown in Figure 4. The clean debonded fibre surfaces in Figure 4 are an indication of 
weak fibre-matrix interfacial adhesion, thus providing minimal resistance to crack propagation. This weak adhesion also results in the fibres pulling out of the fracture surfaces easily, and thus promotes fibre bridging. This results in low fracture energies at initiation which increase significantly with crack length due to fibre bridging, see Table 2.

The SEM images of the GF-Rubber fracture surfaces for the composites cured at $180{ }^{\circ} \mathrm{C}$ are shown in Figure 5(a) and (b), and at $120^{\circ} \mathrm{C}$ in Figure 5(c) and (d). These surfaces are much rougher than those of GF-Control, with residual epoxy adhering to the fibres indicating a stronger fibre-matrix adhesion, see Figure 5(a) and (c). The holes which can be clearly observed in the matrix region on the fracture surfaces are formed by cavitation of the rubber particles followed by void growth of the epoxy matrix. The holes formed by cavitation relieve the constraint on the epoxy and allow large plastic strains in the matrix. The cavities increase in size by plastic void growth due to the triaxial tensile stress state within the plastic zone at the crack tip [73]. The GF-Rubber cured at $120^{\circ} \mathrm{C}$ showed more matrix deformation, as evident from the elongated cavities shown in Figure 5(d), compared with the composite cured at $180^{\circ} \mathrm{C}$, see Figure $5(\mathrm{~b})$. This larger plastic strain in the matrix before failure correlates well with the increase in ductility due to the lower matrix crosslink density, as discussed in Section 3.5 below. The deformation after the cavitation process further increased the fracture energy, giving a larger fracture energy for the composite cured at the lower temperature, see Table 2.

The fracture surfaces of the GF-NS composites are shown in Figure 6, and the images reveal clean debonded fibres indicating relatively poor fibre-matrix adhesion, see Figure 6(a). The poor fibre-matrix adhesion was also observed for the control composite, indicatring that the addition of the silane-treated silica nanoparticles does not affect the adhesion of the matrix to the fibres. There are well adhered silica nanoparticles in the epoxy matrix which suggest that particle debonding and void growth do not occur for composites cured at $180^{\circ} \mathrm{C}$, see Figure $6(\mathrm{~b})$ and 120 ${ }^{\circ} \mathrm{C}$, see Figure 6 (c). If so, then a major toughening mechanism associated with the use of silica nanoparticles is absent. This observation is in agreement with the very low fracture energies shown in Table 2, where the GIC,Init values for GF-NS are lower than those of the GF-Control, and $\mathrm{G}_{\mathrm{IC} \text {,Prop }}$ for the GF-NS cured at $180^{\circ} \mathrm{C}$ was also lower than the corresponding value for GF-Control. It is believed the strong particle-matrix adhesion prevents the NS particles debonding from the 
matrix. The well-bonded and stiff particles constrain the matrix, limiting the matrix deformation during fracture, which fails in a brittle manner and explains the reduced toughness in the system. As for the GF-NS cured at $120^{\circ} \mathrm{C}$, the $20 \%$ increase in the $\mathrm{G}_{\mathrm{IC} \text {,Prop }}$ value compared to GF-Control may simply be due to the fibre bridging and stitching resistance contributions to the overall fracture energy.

For the GF-Hybrid composite, rough fracture surfaces were observed as shown in Figure 7(a). Voids resulting from rubber particle cavitation and void growth are clearly visible in Figure 7(b). However, there was no evidence of debonded silica nanoparticles or voids surrounding silica nanoparticles visible on the surface. This suggests the absence of the silica nanoparticle debonding and plastic void growth mechanism during fracture. This agrees well with the measured toughness, as the fracture energies generally reduced for the GF-Hybrid, see Table 2, or were not significantly different. This is due to the well-bonded and stiff silica nanoparticles which constrain the matrix and reduce its ductility. The fibre to matrix adhesion is relatively good, as shown by the residual epoxy on the surface of the glass fibres. This is similar to that seen for the GF-Rubber, and indeed a similar increase in $\mathrm{G}_{\mathrm{IC}, \text { Prop }}$ compared to $\mathrm{G}_{\mathrm{IC}, \text { Init }}$ is measured for both composites.

In addition to the above toughening mechanisms, the stitching in the composites has been shown to increase the crack propagation resistance during fracture $[71,74,75]$. The stitches break in tension, as shown in Figure 8 (a) and (b), thus contributing to the increase in the fracture energy compared to the bulk polymer.

\subsection{Effect of Crosslink Density on Fracture Energies of GF Composites}

The higher fracture energies for the composites cured at $120^{\circ} \mathrm{C}$ compared with those cured at $180^{\circ} \mathrm{C}$ can be attributed to the effect of matrix crosslink density. The number average molecular weight, $M_{c}$, for the epoxy matrix cured at $120^{\circ} \mathrm{C}$ calculated using Equation 1 is $446 \mathrm{~g} / \mathrm{mol}$, whereas the $M_{c}$ for the epoxy cured at $180{ }^{\circ} \mathrm{C}$ is $375 \mathrm{~g} / \mathrm{mol}$. This means the matrices for the composites cured at $120^{\circ} \mathrm{C}$ have a lower crosslink density, and it is well accepted that they will be more toughenable, hence their higher relative toughness [76].

Microscopy of the fracture surfaces of the GF-NS composite, see Figure 6, showed that the fracture occurred predominantly at the fibre-matrix interface where the debonded fibres showed clean surfaces with few matrix fragments attached. While some studies $[27,28]$ have reported that 
the addition of silica nanoparticles improved the fibre-matrix interfacial adhesion and contributed to the increase in the fracture energies, this effect was not seen in the present work. Tucker et al. [77] showed that longer curing weakens the fibre-matrix interface, but there is little difference in the cure times used here. However, the rigidity and higher bulk modulus of the NS particles will increase the matrix modulus by about $10 \%$ (see Appendix). This increased stiffness may help to promote fibre-matrix interfacial failure rather than matrix fracture.

Some noticeable differences in the matrix deformation between the GF-Rubber cured at 180 ${ }^{\circ} \mathrm{C}$ and $120^{\circ} \mathrm{C}$ have also been observed, as shown in Figure $9(\mathrm{a})$ and (b) respectively. The cavities for the GF-Rubber cured at $120^{\circ} \mathrm{C}$ were found to be highly deformed and elongated, see Figure 9 (a). This behaviour can be attributed to the increase in matrix ductility as a result of lower crosslink density, which enables the matrix to undergo extensive plastic deformation and allowed the cavities to enlarge significantly more after cavitation of the rubber particles occurred in the matrix. The cavities for the composites cured at $180^{\circ} \mathrm{C}$ are smaller than those for the $120{ }^{\circ} \mathrm{C}$ material due to the lower ductility of the matrix, see Figure 9 (b).

\subsection{Fatigue Crack Growth (FCG)}

The FCG curves for all of the GF composites cured at $180^{\circ} \mathrm{C}$ are shown in Figure 10 . The curves exhibit a sigmoidal shape as expected, and show good repeatability and low scatter. The fatigue threshold is reached when the crack growth rate decreases to negligible values. A pronounced knee indicating a clear fatigue threshold was observed in all cases.

The values of the quasi-static fracture energy, $G_{\mathbb{C}}$, and fatigue threshold fracture energy, $G_{t h}$, are summarised in Table 3. The results show that the fatigue threshold fracture energy is much lower than the quasi-static value, indicating how damaging fatigue loading is to the composites.

The comparison of the fatigue crack growth rate and fatigue threshold for the GF composites is shown in Figure 10. The graphs clearly indicate that the use of rubber-modified and silica nanoparticle-modified matrices, see Figure $10(b)$ and (c), reduces significantly the fatigue crack growth rate in Region II as well as increasing the threshold fracture energies to approximately double that of the control samples shown in Figure 10(a). The fatigue threshold was further increased to 3.5 times the GF-Control value when using the hybrid modified epoxy matrix, see 
Figure 10(d), suggesting an additive or a synergistic toughening effect between the rubber particles and the silica nanoparticles in fatigue.

\subsection{Plastic Zone Size}

As the toughening is dependent on the size of the plastic zone ahead of the crack tip, it is of interest to show that the size of the plastic zone at the threshold is larger than the size of the toughening particles, such that these particles are enclosed within the plastic zone and hence actively toughen the material. The plastic zone size under plane strain conditions was calculated using Equation 6, assuming that the zone is circular and that cracks occur within the matrix-rich region. The radius of the plastic zone in $\mathrm{m}, \mathrm{r}_{\mathrm{y}}$, is given by

$$
r_{y}=\frac{1}{6 \pi}\left(\frac{K_{I C}}{\sigma_{y}}\right)^{2}
$$

Equation 6

where $\mathrm{K}_{\mathrm{IC}}$ is the fracture toughness in MPa $\mathrm{m}^{1 / 2}$, and $\sigma_{\mathrm{y}}$ is the yield stress in MPa.

The plastic zone size at propagation was calculated using the bulk polymer properties ( $\mathrm{K}_{\mathrm{IC}}$, $\mathrm{G}_{\mathrm{IC}}, \mathrm{E}$ and $\sigma_{\mathrm{y}}$ ) taken from [50]. The plastic zone size at threshold uses the fatigue threshold values reported in Table 3. In the threshold region, the applied strain energy release rate and the zone size are at a minimum.

The calculated $r_{y}$ values are presented in Table 4, and show that the size of the plastic zone increases with the addition of the toughening particles in both propagation and threshold regions, compared to the control. It is also clear that the plastic zone sizes in the toughened composites, where $r_{y}=4.6$ to $11.6 \mu \mathrm{m}$, are substantially larger than the undeformed rubber particles and silica nanoparticles measured as $1.25 \mu \mathrm{m}$ [50] and $10 \mathrm{~nm}$ [15] in radius respectively. The results also explain why the addition of CTBN and the addition of silica nanoparticles both increased the $\mathrm{G}_{\mathrm{th}}$ value, as the plastic zones are large enough to encompass the particles and hence allow the toughening mechanisms to operate even at the fatigue threshold. Thus the particles are actively toughening the composites at the fatigue threshold, as is confirmed by the $\mathrm{G}_{\text {th }}$ values for the toughened formulations being greater than for the GF-Control. Further, in the GF-Hybrid the fatigue threshold fracture energy is increased further, indicating that both types of particles are actively toughening the material. 
It is also noted that curing the composites at a lower temperature generally increased the plastic zone size. These increases can be attributed to the lower crosslink density in the epoxy matrix, which increases its ductility and allows more matrix deformation to occur.

\subsection{Microscopy of Fatigue Fracture Surfaces}

Images of the fatigue fracture surfaces of the specimens were taken in the threshold region. These were similar to the quasi-static fracture surfaces, although in fatigue the surfaces are relatively smooth when compared to the quasi-static fracture [78]. Energy absorbing mechanisms similar to those seen in the quasi-static tests would be expected to occur in fatigue. However, there is less deformation of the epoxy matrix than for quasi-static fracture, which is expected due to the low measured fracture energies at threshold [79].

\subsubsection{GF Composites with Unmodified Matrices (GF-Control)}

Low magnification SEM images of the fatigue fracture surfaces for the GF-Control composites are shown in Figure 11. Microscopic features such as broken fibres, fibre bridging and fibre debonding were observed in this area, see Figure 11(b). Clean debonded fibres were an indication that the fracture occurred predominantly at the fibre-matrix interface due to weak interfacial adhesion, see Figure 11(c). There was also evidence of stitch tensile breakage and debonded stitching thread which resulted in a crisscross pattern on the surface, see Figure 11(a). This suggests that the crack did not remain in the mid-plane but branched out to neighbouring plies following a zigzag crack propagation pattern resulting in uneven fracture surfaces. The zigzag crack pattern is normally found on laminates with $0^{\circ} / 90^{\circ}$ midply interfaces [62]. The formation of scarps and riverlines in the resin rich area shown in Figure 11(d) are common signs of brittle matrix fracture. The few microscopic features observed correspond well with the low fracture energies.

\subsubsection{GF Composites with Rubber-Modified Matrices (GF-Rubber)}

The SEM images of the fatigue fracture surfaces of the GF-Rubber samples are shown in Figure 12. As for the GF-Control, the fracture did not always propagate on the same plane, but periodically cracking and branching occurred between the two neighbouring $0^{\circ} / 90^{\circ}$ interfaces at the midplane, see Figure 12(a).

The high magnification images in Figure 12(c) and (d) show a higher degree of surface roughness and extensive matrix deformation with voided rubber particles. This increases the 
fracture resistance during crack growth, hence providing a higher fracture energy. The voids are formed due to cavitation of the rubber particles followed by void growth via plastic deformation of the epoxy matrix. Once cavitation has occurred, the reduction of constraint on the matrix allows the epoxy to plastically deform and absorb energy. These mechanisms are responsible for the increase in the fracture energy. Based on the void distribution shown in the image, the rubber particles were dispersed relatively homogeneously across the entire matrix, with no agglomeration being observed. Cavitation also indicates that there is excellent adhesion between the phaseseparated CTBN rubber and the epoxy matrix. The voids in Figure 12(d) vary in size as they were fractured at a random plane, resulting in cavities appearing smaller than their true diameter if they fractured away from their equator.

The embedded fibres with matrix epoxy attached, see Figure 12(b) and (c), indicate a relatively good fibre-matrix adhesion. The increased interfacial adhesion as well as the matrix toughness contributes to a higher fracture energy in GF-Rubber when compared to GF-Control. An interesting point to note is that there is a distinct feature between propagation and threshold regions during fatigue fracture. In the propagation region, the rubber cavitations and matrix deformation were stronger than those of the threshold suggesting these mechanisms were actively toughening. In the threshold region, smaller cavities and less matrix deformation were observed due to the decrease in the crack growth rate and active toughening mechanisms due to the smaller plastic zone at the crack tip compared to the quasi-static tests.

\subsubsection{GF Composites with Silica Nanoparticle-Modified Matrices (GF-NS)}

The low magnification SEM images of the GF-NS fatigue fracture surfaces are shown in Figure 13. Fracture occurred predominantly at the fibre-matrix interface resulting in clean debonded fibres, see Figure 13(b), as was observed for quasi-static fracture. These debonded fibres bridged the crack as it propagated, leaving loose broken fibres on the surface, see Figure 13(a). Brittle matrix fracture was observed in the resin rich area. Evidence of stitch tensile breakage suggests that the crack propagated through the biaxial fabric and did not remain on the same plane as the film insert.

High magnification images of the matrix fracture surface after fatigue loading are shown in Figure 14. There was a good dispersion of the silica nanoparticles throughout the matrix and 
significant debonding occurred in this region. Individual silica nanoparticles can be identified as almost spherical features in Figure 14(b). Figure 14(a) shows some voids after debonding of silica nanoparticles; some of these voids are circled in Figure 14(a). These voids appeared smaller than the particles, but this is likely to be the effect of the sputtered chromium coating deposited on the fracture surface, which affected the size of both voids and the particles. The coating partially covered the voids making them appeared smaller than the actual hole size or shadowed the particles and resulted in an increase in the particle diameter causing them to appear larger than their true size [80]. The presence of debonded silica nanoparticles and plastic void growth in this region is in accordance with the increase in the threshold fracture energy compared to the GFControl, whose fracture surfaces are featureless.

\subsubsection{GF Composites with Hybrid-Modified Matrices (GF-Hybrid)}

The low magnification SEM images of the GF-Hybrid shown in Figure 15(a) and (b) revealed that similar fracture processes involving matrix fracture, fibre debonding and pull-out, crack branching and jumping between plies occurred. These surfaces also exhibited very high surface roughness, where there was a significant amount of matrix adhering to the fibres, see Figure 15(a), and extensive matrix deformation in the resin rich region, see Figure 15(b). This indicates a good interfacial adhesion between the fibres and the matrix, as shown in Figure 16(a) and (b), which contributes to the higher fracture resistance.

For the fatigue specimens, evidence of rubber particle cavitation can be observed at higher magnifications, as shown in Figure 16(c). Some of the cavities appeared to have internal voids, which are believed to be epoxy particles within the rubber particles resulting from local phaseinversion, see Figure 16(c). Rubber particle cavitation and debonded silica nanoparticles can be seen in Figure 16(d), with plastic void growth of the epoxy matrix. However, the void growth around the silica nanoparticles is hard to identify due to the thickness of the conductive coating which shadowed the nanoparticles and voids on the surface. The fracture energies at threshold for GFHybrid in Table 3 were much higher than the control and other toughened composites. This suggests that the toughening mechanisms from the silica nanoparticles were operative in this region in addition to those from cavitation of the rubber particles and from the fibre toughening effect. 


\subsection{Relationship between Quasi-static and Fatigue Fracture}

The relationship between the quasi-static and fatigue fracture behaviour of the GF composites is summarised in Figure 17, and is analysed by considering the ratio of the fatigue threshold $G_{\text {th }}$ over the $G_{\mathrm{IC}, \text { Prop }}$ from the quasi-static tests. This ratio is a measure of sensitivity of a sample to fatigue loading [38]. Generally, a higher ratio is preferred as not only does this indicate excellent toughening performance under both static and fatigue conditions, it also indicates that the fatigue threshold energy is closer to the quasi-static value. A low $G_{t h} / G_{l C}$ ratio indicates that the sample is sensitive to fatigue loading and has a high possibility to fail in fatigue at a small fraction of the quasi-static failure load, hence special design requirements are required if fatigue loads are expected in service [38]. The $\mathrm{G}_{\mathrm{th}} / \mathrm{G}_{\mathrm{IC}}$ ratio for GF-Control (i.e. $7 \%$ ) was taken as the baseline, and is shown as the lower dashed line in Figure 17 . The ratio of $10 \%$ is typical for epoxy adhesives in bonded composite joints [81], and is also shown as the upper dashed line in Figure 17.

Figure 17 confirms that the addition of CTBN rubber and silica nanoparticles into GF composite matrices greatly increases the $\mathrm{G}_{\mathrm{th}} / \mathrm{G}_{\mathrm{IC}}$ ratio, to a much higher value than the two reference lines. This indicates that the hybrid modified composites perform much better in fatigue than typical epoxy polymers. The addition of NS to the rubber modified epoxy to form a hybrid greatly improves the fatigue performance. Overall it can be seen that the addition of rubber improves $\mathrm{G}_{\mathrm{IC}}$, and the further addition of NS improves $\mathrm{G}_{\mathrm{th}}$.

\subsection{Synergistic Effect}

The threshold fracture energy of the hybrid shows an apparent synergy, where the measured $\mathrm{G}_{\text {th }}$ value is greater than expected from the individual values for the GF-Rubber and GF-NS composites. The synergy of the GF-Hybrid can be analysed quantitatively, by comparing the measured threshold fracture energy to the sum of the increments of the values for the GF composites toughened with the individual particles using

$$
G_{t h} \text { Hybrid }=G_{t h} \text { Control }+\Delta G_{t h} R u b b e r+\Delta G_{t h} N S \quad \text { Equation } 7
$$

The threshold fracture energies and the calculated increments are shown in Table 5. Using Equation 6, the predicted threshold fracture energy assuming that the effect is additive is $195 \mathrm{~J} / \mathrm{m}^{2}$. This can be compared to the measured $\mathrm{G}_{\mathrm{th}}$ for the GF-Hybrid which is $249 \mathrm{~J} / \mathrm{m}^{2}$, see Table 4, 
which is approximately $22 \%$ higher than the additive prediction. This clearly shows a synergy for the hybrid composite. The addition of NS to the rubber modified epoxy to form the hybrid greatly improves the fatigue performance. Kim et al. [5] proposed that the addition of ceramic particles compensated for the effect of the rubber particles on the plastic deformation of the matrix when these particles are present together in the epoxy, allowing a large increase in the fracture energy. Here the relief of constraint caused by the voids formed by one particle allows greater deformation of the epoxy matrix and hence improves the fatigue performance.

Overall it can be seen for the composites that the addition of rubber improves $\mathrm{G}_{\mathrm{IC}}$, and the further addition of silica nanoparticles improves $\mathrm{G}_{\mathrm{th}}$. The addition of both particle types to the epoxy gives a synergistic effect which greatly improves the threshold fracture energy. This highlights the effectiveness of combining different types of particles to form hybrid toughened systems. This approach, of using micron-sized particles to increase $G_{I C}$ and nanoparticles to improve $G_{t h}$, is applicable to a wide range of other composite matrices, inclusing thermoplastic- and core-shell rubber-toughened systems. It is also applicable to nanoparticles of other sizes, and of other types.

\section{Conclusions}

The static and fatigue fracture behaviour for toughened amine-cured epoxy glass fibre (GF) composites were investigated, and their related toughening mechanisms were identified by microscopy. The fatigue fracture performance of fibre composites toughened with carboxylterminated butadiene-acrylonitrile (CTBN) and silica nanoparticles are reported for the first time. The CTBN rubber generally phase-separated completely, to form micron-sized particles. The GF composites cured at $120^{\circ} \mathrm{C}$ showed a greater toughening effect with the addition of rubber or silica nanoparticles than those cured at $180^{\circ} \mathrm{C}$ due to the higher ducility from the lower matrix crosslink density.

A large increase in the interlaminar fracture energy, $G_{I C}$, was observed for the GF-Rubber but there was no significant increase for the GF-NS. In fatigue, both GF-Rubber and GF-NS showed an increased fatigue threshold strain energy release rate, $G_{t h}$, and reduced fatigue crack growth rate when compared to GF-Control. A synergistic effect of these particles in the GF-Hybrid was also identified. 
Microscopy showed that cavitation of the rubber particles and debonding of the silica nanoparticles, both of which were followed by plastic void growth mechanisms were the main energy contributors that increased the fracture energy in the toughened composites. In fatigue, when the plastic zone at the crack tip is much smaller, the nanoparticle toughening mechanisms are active, and hence the fatigue threshold is greatly improved.

Overall it can be seen that the addition of the micron-sized particles improves $\mathrm{G}_{\mathrm{IC}}$, and the further addition of the nanoparticles improves $G_{t h}$ for the composites. Thus this same approach can also be used for other types and sizes of nanoparticles. The addition of both particle types to the epoxy gives a synergistic effect which greatly improves the threshold fracture energy.

This highlights the effectiveness of combining micro- and nanoparticles to form hybrid toughened systems, indicating a potent route to increase both the static and fatigue fracture performance of fibre composites and hence their service life or the safety of composite structures. The approach developed here is readily transferable to a wide range of composite systems, using other particle sizes and types.

\section{Acknowledgements}

This work was supported by the Malaysian Government Agency, MARA with a PhD studentship for Dr Shamsiah Awang Ngah, and by the Department of Mechanical Engineering at Imperial College London. The authors would also like to thank Evonik, Germany for materials and technical support. Some of the equipment used was provided by Dr. Taylor's Royal Society Mercer Junior Award for Innovation.

\section{References}

[1] Yan C, Xiao K, Ye L, Mai Y-W. Numerical and experimental studies on the fracture behavior of rubbertoughened epoxy in bulk specimen and laminated composites. Journal of Materials Science. 2002;37(5):9217.

[2] Kumar P, Singh RK. Impact damage area and interlaminar toughness of modified FRP laminates. Advanced Composite Materials. 2000;9(2):77-88.

[3] Sue HJ, Jones RE, Garcia-Meitin El. Fracture behaviour of model toughened composites under Mode I and Mode II delaminations. Journal of Materials Science. 1993;28(23):6381-91.

[4] Hunston DL, Moulton RJ, Johnston NJ, Bascom WD. Matrix resin effects in composite delamination : Mode I fracture aspects. Toughened Composites, ASTM STP. 1987;937:74-94. 
[5] Kim J, Baillie C, Poh J, Mai Y-W. Fracture toughness of CFRP with modified epoxy resin matrices. Composites Science and Technology. 1992;43(3):283-97.

[6] Bonnaud L, Pascault JP, Sautereau H, Zhao JQ, Jia DM. Effect of reinforcing glass fibers on morphology and properties of thermoplastic modified epoxy-aromatic diamine matrix. Polymer Composites. 2004;25(4):368-74.

[7] Mujika F, De Benito A, Fernández B, Vázquez A, Llano-Ponte R, Mondragon I. Mechanical properties of carbon woven reinforced epoxy matrix composites. A study on the influence of matrix modification with polysulfone. Polymer Composites. 2002;23(3):372-82.

[8] Wetzel B, Rosso P, Haupert F, Friedrich K. Epoxy nanocomposites - fracture and toughening mechanisms. Engineering Fracture Mechanics. 2006;73(16):2375-98.

[9] Wetzel B, Haupert F, Qiu Zhang M. Epoxy nanocomposites with high mechanical and tribological performance. Composites Science and Technology. 2003;63(14):2055-67.

[10] Lee J, Yee AF. Fracture of glass bead/epoxy composites: on micro-mechanical deformations. Polymer. 2000;41(23):8363-73.

[11] Lee J, Yee AF. Inorganic particle toughening II: toughening mechanisms of glass bead filled epoxies. Polymer. 2001;42(2):589-97.

[12] Lee J, Yee AF. Inorganic particle toughening I: micro-mechanical deformations in the fracture of glass bead filled epoxies. Polymer. 2001;42(2):577-88.

[13] Nakamura Y, Yamaguchi M, Okubo M, Matsumoto T. Effects of particle size on mechanical and impact properties of epoxy resin filled with spherical silica. Journal of Applied Polymer Science. 1992;45(7):1281-9.

[14] Kawaguchi T, Pearson RA. The effect of particle-matrix adhesion on the mechanical behavior of glass filled epoxies. Part 2. A study on fracture toughness. Polymer. 2003;44(15):4239-47.

[15] Johnsen BB, Kinloch AJ, Mohammed RD, Taylor AC, Sprenger S. Toughening mechanisms of nanoparticle-modified epoxy polymers. Polymer. 2007;48(2):530-41.

[16] Bagheri R, Marouf BT, Pearson RA. Rubber-toughened epoxies: A critical review. Polymer Reviews. 2009;49(3):201-25.

[17] Chen J, Taylor AC. Epoxy modified with triblock copolymers: morphology, mechanical properties and fracture mechanisms. Journal of Materials Science. 2012;47(11):4546-60.

[18] Van Velthem P, Ballout W, Horion J, Janssens YA, Destoop V, Pardoen T, et al. Morphology and fracture properties of toughened highly crosslinked epoxy composites: A comparative study between high and low $\mathrm{Tg}$ tougheners. Composites Part B: Engineering. 2016;101(Supplement C):14-20.

[19] He R, Zhan X, Zhang Q, Chen F. Improving the toughness of epoxy with a reactive tetrablock copolymer containing maleic anhydride. Journal of Applied Polymer Science. 2016;133(1).

[20] Carolan D, Ivankovic A, Kinloch AJ, Sprenger S, Taylor AC. Toughened carbon fibre-reinforced polymer composites with nanoparticle-modified epoxy matrices. Journal of Materials Science. 2017;52(3):1767-88.

[21] Awang Ngah S, Taylor AC. Toughening performance of glass fibre composites with core-shell rubber and silica nanoparticle modified matrices. Composites Part A: Applied Science and Manufacturing. 2016;80:292303.

[22] Quan D, Ivankovic A. Effect of core-shell rubber (CSR) nano-particles on mechanical properties and fracture toughness of an epoxy polymer. Polymer. 2015;66(Supplement C):16-28.

[23] Marouf BT, Mai Y-W, Bagheri R, Pearson RA. Toughening of Epoxy Nanocomposites: Nano and Hybrid Effects. Polymer Reviews. 2016;56(1):70-112. 
[24] Kinloch AJ, Mohammed RD, Taylor AC, Eger C, Sprenger S, Egan D. The effect of silica nano particles and rubber particles on the toughness of multiphase thermosetting epoxy polymers. Journal of Materials Science. 2005;40(18):5083-6.

[25] Kinloch AJ, Mohammed RD, Taylor AC, Sprenger S, Egan D. The interlaminar toughness of carbon-fibre reinforced plastic composites using 'hybrid-toughened' matrices. Journal of Materials Science. 2006;41(15):5043-6.

[26] Hsieh TH, Kinloch AJ, Masania K, Sohn Lee J, Taylor AC, Sprenger S. The toughness of epoxy polymers and fibre composites modified with rubber microparticles and silica nanoparticles. Journal of Materials Science. 2010;45(5):1193-210.

[27] Zeng Y, Liu H-Y, Mai Y-W, Du X-S. Improving interlaminar fracture toughness of carbon fibre/epoxy laminates by incorporation of nano-particles. Composites Part B: Engineering. 2012;43(1):90-4.

[28] Tsai J-L, Huang B-H, Cheng Y-L. Enhancing fracture toughness of glass/epoxy composites by using rubber particles together with silica nanoparticles. Journal of Composite Materials. 2009;43(25):3107-23.

[29] Blackman BRK, Kinloch AJ, Sohn Lee J, Taylor AC, Agarwal R, Schueneman G, et al. The fracture and fatigue behaviour of nano-modified epoxy polymers. Journal of Materials Science. 2007;42(16):7049-51.

[30] Manjunatha CM, Taylor AC, Kinloch AJ, Sprenger S. The effect of rubber micro-particles and silica nanoparticles on the tensile fatigue behaviour of a glass-fibre epoxy composite. Journal of Materials Science. 2009;44(1):342-5.

[31] Manjunatha CM, Taylor AC, Kinloch AJ, Sprenger S. The cyclic-fatigue behaviour of an epoxy polymer modified with micron-rubber and nano-silica particles. Journal of Materials Science. 2009;44(16):4487-90.

[32] Hsieh TH, Kinloch AJ, Taylor AC, Kinloch IA. The effect of carbon nanotubes on the fracture toughness and fatigue performance of a thermosetting epoxy polymer. Journal of Materials Science. 2011;46(23):752535.

[33] Bortz DR, Merino C, Martin-Gullon I. Carbon nanofibers enhance the fracture toughness and fatigue performance of a structural epoxy system. Composites Science and Technology. 2011;71(1):31-8.

[34] Khan SU, Munir A, Hussain R, Kim J-K. Fatigue damage behaviors of carbon fiber-reinforced epoxy composites containing nanoclay. Composites Science and Technology. 2010;70(14):2077-85.

[35] Böger L, Sumfleth J, Hedemann H, Schulte K. Improvement of fatigue life by incorporation of nanoparticles in glass fibre reinforced epoxy. Composites Part A: Applied Science and Manufacturing. 2010;41(10):1419-24.

[36] Kostopoulos V, Vavouliotis A, Karapappas P, Loutas T, Voyatzi T, Paipetis A. Multi-stage fatigue life monitoring on carbon fibre reinforced polymers enhanced with multi-wall carbon nanotubes. Proc Eur Conf Compos Mater(ECCM)2008.

[37] Zhou Y, Pervin F, Jeelani S, Mallick P. Improvement in mechanical properties of carbon fabric-epoxy composite using carbon nanofibers. Journal of Materials Processing Technology. 2008;198(1):445-53.

[38] Ashcroft IA, Shaw SJ. Mode I fracture of epoxy bonded composite joints 2. Fatigue loading. International Journal of Adhesion and Adhesives. 2002;22(2):151-67.

[39] Pirondi A, Nicoletto G. Fatigue crack growth in bonded DCB specimens. Engineering Fracture Mechanics. 2004;71(4-6):859-71.

[40] Hojo M, Ando T, Tanaka M, Adachi T, Ochiai S, Endo Y. Modes I and II interlaminar fracture toughness and fatigue delamination of CF/epoxy laminates with self-same epoxy interleaf. International Journal of Fatigue. 2006;28(10):1154-65.

[41] Hojo M, Matsuda S, Tanaka M, Ochiai S, Murakami A. Mode I delamination fatigue properties of interlayertoughened CF/epoxy laminates. Composites Science and Technology. 2006;66(5):665-75. 
[42] Hojo M, Nakashima K, Kusaka T, Tanaka M, Adachi T, Fukuoka T, et al. Mode I fatigue delamination of Zanchor-reinforced CF/epoxy laminates. International Journal of Fatigue. 2010;32(1):37-45.

[43] Byrd LW, Birman V. The estimate of the effect of z-pins on the strain release rate, fracture and fatigue in a composite co-cured z-pinned double cantilever beam. Composite Structures. 2005;68(1):53-63.

[44] Grimmer CS, Dharan C. Enhancement of delamination fatigue resistance in carbon nanotube reinforced glass fiber/polymer composites. Composites Science and Technology. 2010;70(6):901-8.

[45] Hexion Specialty Chemicals Inc. Epikote ${ }^{\mathrm{TM}}$ Resin 862/ Epikure ${ }^{\mathrm{TM}}$ Curing W System. Product Bulletin. Texas, USA2001.

[46] Mattsson D. Mechanical performance of NCF composites [PhD Thesis Online]. Sweden: Luleå University of Technology; 2005.

[47] Sprenger S. Epoxy resin composites with surface-modified silicon dioxide nanoparticles: A review. Journal of Applied Polymer Science. 2013;130(3):1421-8.

[48] Nanoresins AG. Nanopox F400. Technical Datasheet. Germany April 2006.

[49] Johnson WS, Mangalgiri PD. Investigation of fiber bridging in double cantilever beam specimens. National Aeronautics and Space Administration Hampton VA Langley Research Center; 1986.

[50] Awang Ngah S. Static and fatigue behaviour of fibre composites infused with rubber-and silica nanoparticle-modified epoxy [PhD Thesis]. UK: Imperial College London; 2013.

[51] Masania K. Toughening mechanisms of silica nanoparticle-modified epoxy polymers [PhD Thesis]. UK: Imperial College London; 2010.

[52] Hsieh TH, Kinloch AJ, Masania K, Taylor AC, Sprenger S. The mechanisms and mechanics of the toughening of epoxy polymers modified with silica nanoparticles. Polymer. 2010;51(26):6284-94.

[53] American Society for Testing and Materials. Standard Test Method for Mode I Interlaminar Fracture Toughness of Unidirectional Fiber-Reinforced Polymer Matrix Composites ASTM D5528-01 West Conshohocken, PA 19428-2959, United States: ASTM International; 2001.

[54] British Standards Institute. Fibre-reinforced Plastic Composites - Determination of Mode I Interlaminar Fracture Toughness, GIc, for Unidirectionally Reinforced Materials BS ISO 15024:2001 London: BSI; 2001.

[55] Hodgkinson JM. Mechanical testing of advanced fibre composites. Cambridge: Woodhead Publishing; 2000. p. xv, 362 p.

[56] Qian W, Sun CT. Calculation of stress intensity factors for interlaminar cracks in composite laminates. Composites Science and Technology. 1997;57(6):637-50.

[57] de Morais AB, de Moura MF, Gonçalves JPM, Camanho PP. Analysis of crack propagation in double cantilever beam tests of multidirectional laminates. Mechanics of Materials. 2003;35(7):641-52.

[58] Pereira AB, de Morais AB, de Moura MFSF, Magalhães AG. Mode I interlaminar fracture of woven glass/epoxy multidirectional laminates. Composites Part A: Applied Science and Manufacturing. 2005;36(8):1119-27.

[59] Pereira AB, de Morais AB. Mixed mode I+II interlaminar fracture of glass/epoxy multidirectional laminates - Part 2: Experiments. Composites Science and Technology. 2006;66(13):1896-902.

[60] Siddiqui NA, Woo RSC, Kim J-K, Leung CCK, Munir A. Mode I interlaminar fracture behavior and mechanical properties of CFRPs with nanoclay-filled epoxy matrix. Composites Part A: Applied Science and Manufacturing. 2007;38(2):449-60.

[61] Mouritz AP, Baini C, Herszberg I. Mode I interlaminar fracture toughness properties of advanced textile fibreglass composites. Composites Part A: Applied Science and Manufacturing. 1999;30(7):859-70. 
[62] de Morais AB, de Moura MF, Marques AT, de Castro PT. Mode-I interlaminar fracture of carbon/epoxy cross-ply composites. Composites Science and Technology. 2002;62(5):679-86.

[63] American Society for Testing and Materials. Standard Test Method for Measurement of Fatigue Crack Growth Rates, ASTM E 647-00 West Conshohocken, PA 19428-2959, United States: ASTM International; 2000.

[64] British Standards Institute. Fibre-reinforced Plastics - Determination of Fatigue Properties under Cyclic Loading Conditions. BS ISO 13003 : 2003 London: BSI; 2003.

[65] Virkler DA, Hillberry, B. M.,Goel, P. K. The statistical nature of fatigue crack propagation. Technical Report AFFDL-TR-78-43. 1979;101:148-53.

[66] Wise CW, Cook WD, Goodwin AA. CTBN rubber phase precipitation in model epoxy resins. Polymer. 2000;41(12):4625-33.

[67] Hussain F, Chen J, Hojjati M. Epoxy-silicate nanocomposites : Cure monitoring and characterization. Materials Science and Engineering : A. 2007;445-446:467-76.

[68] Okoro CU, Hossain MK, Hosur MV, Jeelani S. Mechanical Characterization of XD-Grade Carbon Nanotube/Epon 862 Processed by Dual Phase Dispersion Technique. Journal of Engineering Materials and Technology. 2011;133(4):041009--4.

[69] Fox TG. Influence of diluent and of copolymer composition on the glass temperature of a polymer system. Bull Am Phys Soc. 1956;1(2):123-35.

[70] Robinson P, Hodgkinson JM. Interlaminar fracture toughness. In: Hodgkinson JM, editor. Mechanical testing of advanced fibre composites. Cambridge: Woodhead Publishing Limited; 2000. p. 170-207.

[71] Tan KT, Watanabe N, Sano M, Iwahori Y, Hoshi H. Interlaminar Fracture Toughness of Vectran-stitched Composites - Experimental and Computational Analysis. Journal of Composite Materials. 2010;44(26):320329.

[72] Kim J-K, Sham M-L. Impact and delamination failure of woven-fabric composites. Composites Science and Technology. 2000;60(5):745-61.

[73] Huang Y, Kinloch AJ, Bertsch RJ, Siebert AR. Particle-matrix interfacial bonding. Effect on the fracture properties of rubber-modified epoxy polymers. In: Riew CK, Kinloch AJ, editors. Toughened Plastics I. Washington DC: American Chemical Society; 1993. p. 189-210.

[74] Dransfield KA, Jain LK, Mai Y-W. On the effects of stitching in CFRPs-I. Mode I delamination toughness. Composites Science and Technology. 1998;58(6):815-27.

[75] Tan K, Watanabe N, Iwahori Y. Stitch fiber comparison for improvement of interlaminar fracture toughness in stitched composites. Journal of Reinforced Plastics and Composites. 2011;30(2):99-109.

[76] Liu J, Sue HJ, Thompson ZJ, Bates FS, Dettloff M, Jacob G, et al. Effect of crosslink density on fracture behavior of model epoxies containing block copolymer nanoparticles. Polymer. 2009;50(19):4683-9.

[77] Tucker R, Compston P, Jar PYB. The effect of post-cure duration on the mode I interlaminar fracture toughness of glass-fibre reinforced vinylester. Composites Part A: Applied Science and Manufacturing. 2001;32(1):129-34.

[78] Njuguna J, Pielichowski K, Alcock JR. Epoxy-Based Fibre Reinforced Nanocomposites. Advanced Engineering Materials. 2007;9(10):835-47.

[79] Kinloch A, Lee S, Taylor A. Improving the fracture toughness and the cyclic-fatigue resistance of epoxypolymer blends. Polymer. 2014;55(24):6325-34 .

[80] Sohn Lee J. The fatigue behaviour of nano-modified epoxy adhesives [PhD Thesis]. UK: Imperial College London; 2009. 
[81] Johnson WS, Butkus LM, Valentin RV. Applications of fracture mechanics to the durability of bonded composite joints. Georgia Inst of Tech Atlanta School of Mechanical Engineering. 1998.

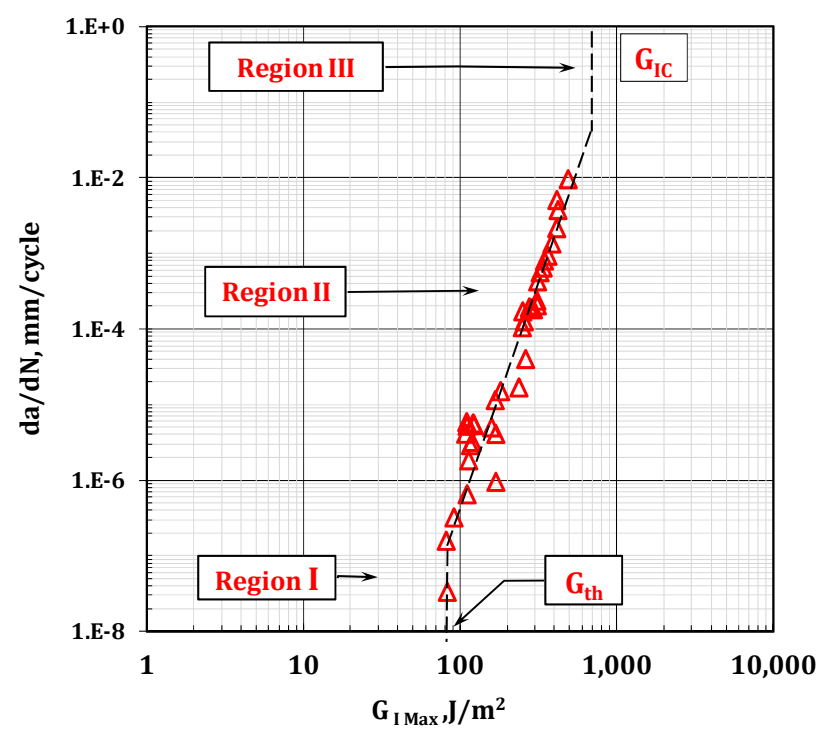

Figure 1 : Typical plot of fatigue crack growth per cycle, da/dN, vs. maximum applied strain energy release rate, $G_{I}$ Max

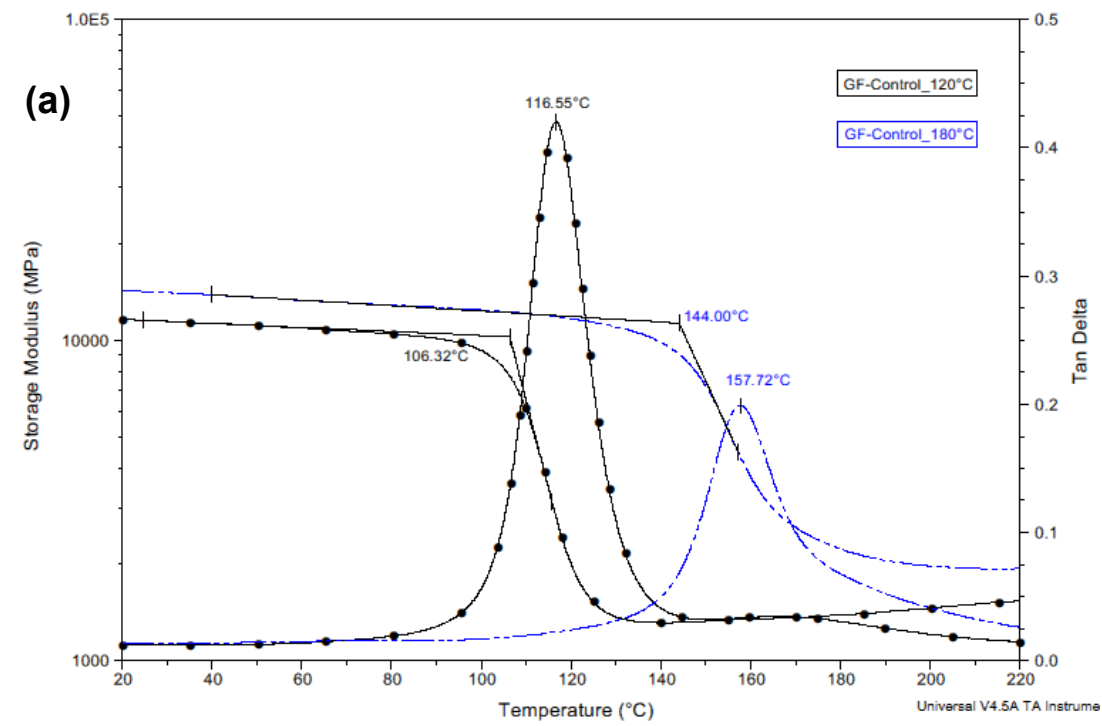



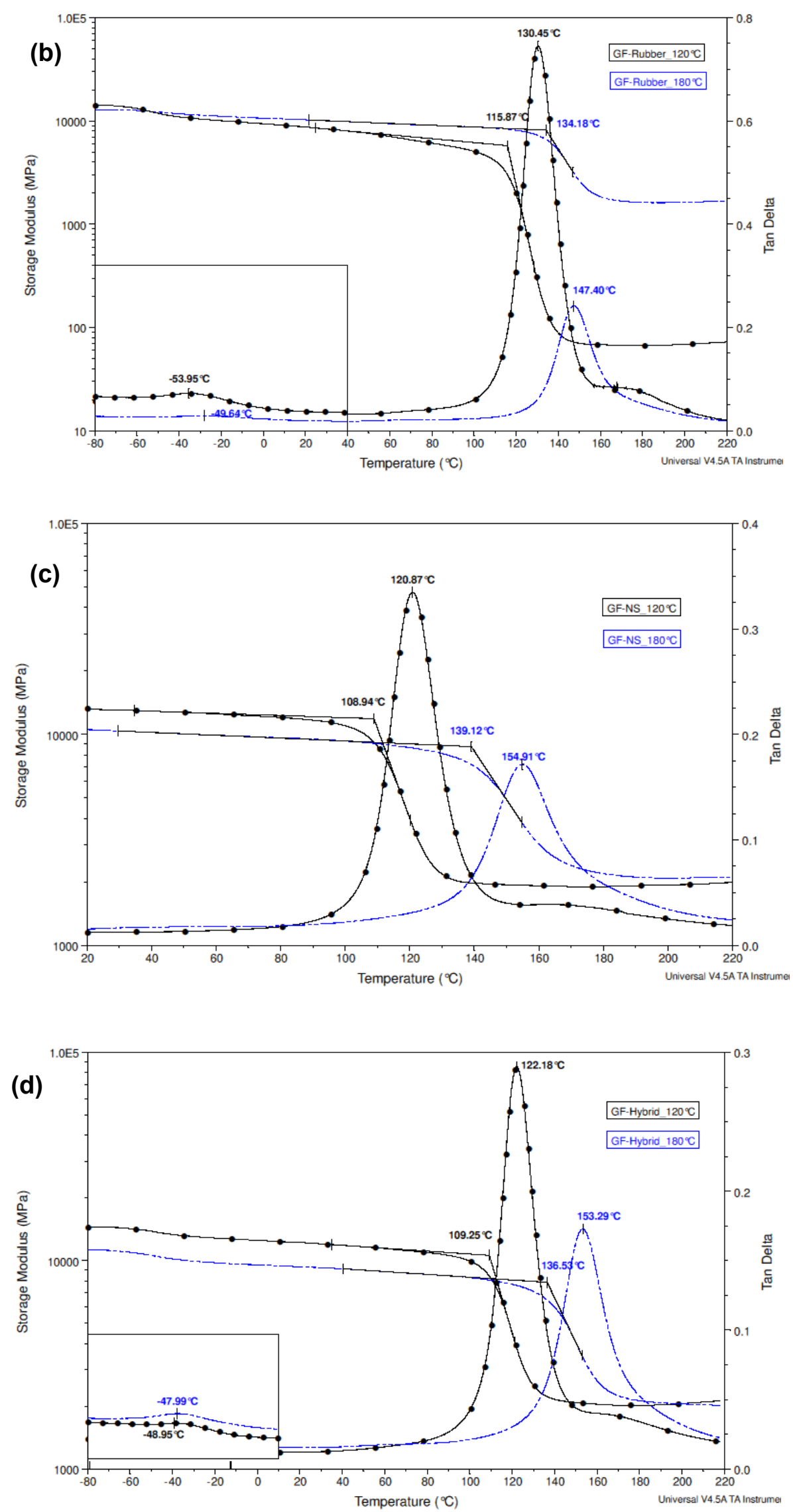

Figure 2 : Typical DMA curves for GF composites cured at $120^{\circ} \mathrm{C}$ and $180^{\circ} \mathrm{C}$. (a) GF-Control, (b) GF-Rubber, (c) GF-NS, and (d) GF-Hybrid. Inset view for (b) and (d) showing the $T_{g}$ for rubber particles. 
(a)

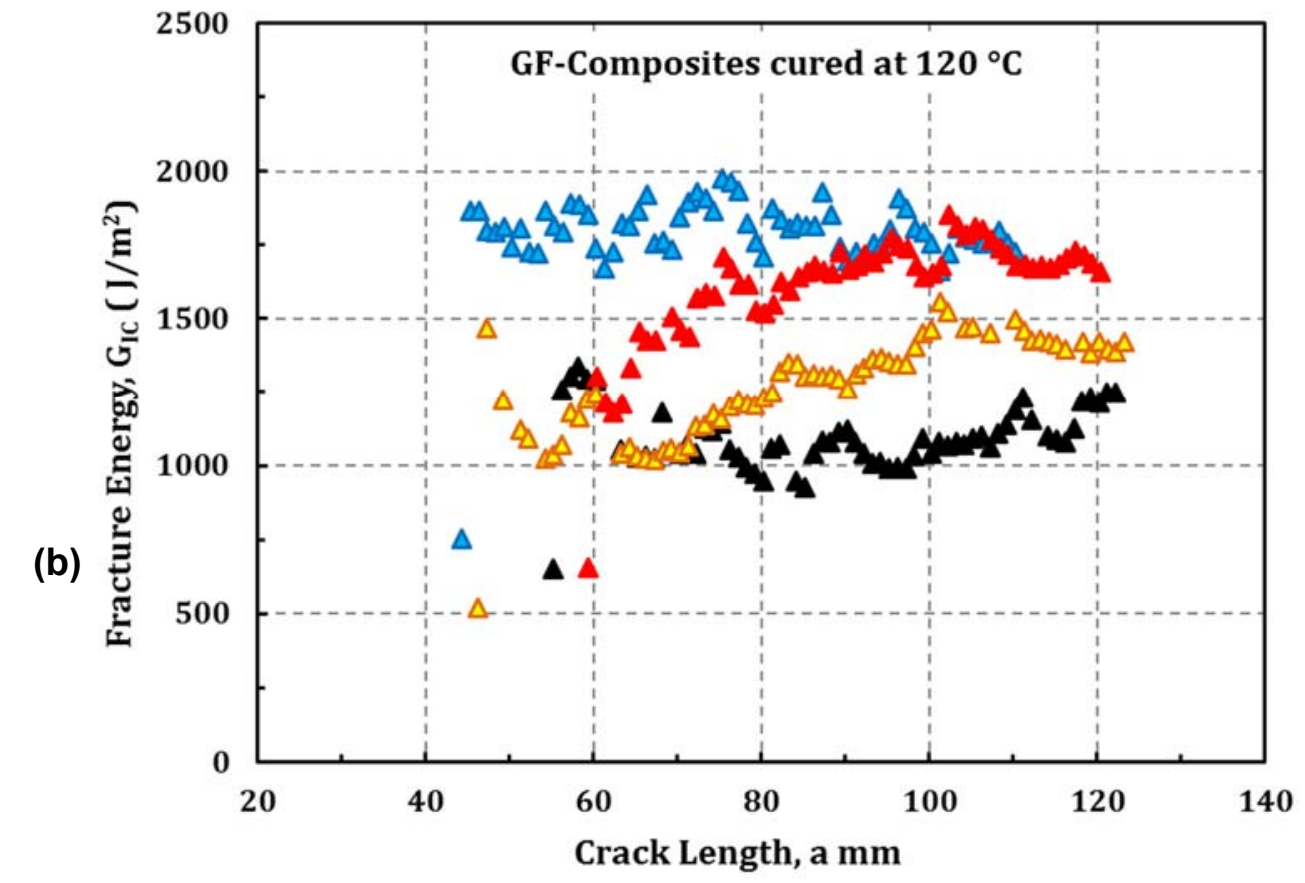

(b) $\quad \Delta$ GF-Control $\quad \Delta$ GF-Rubber $\quad \Delta$ GF-NS $\Delta$ GF-Hybrid

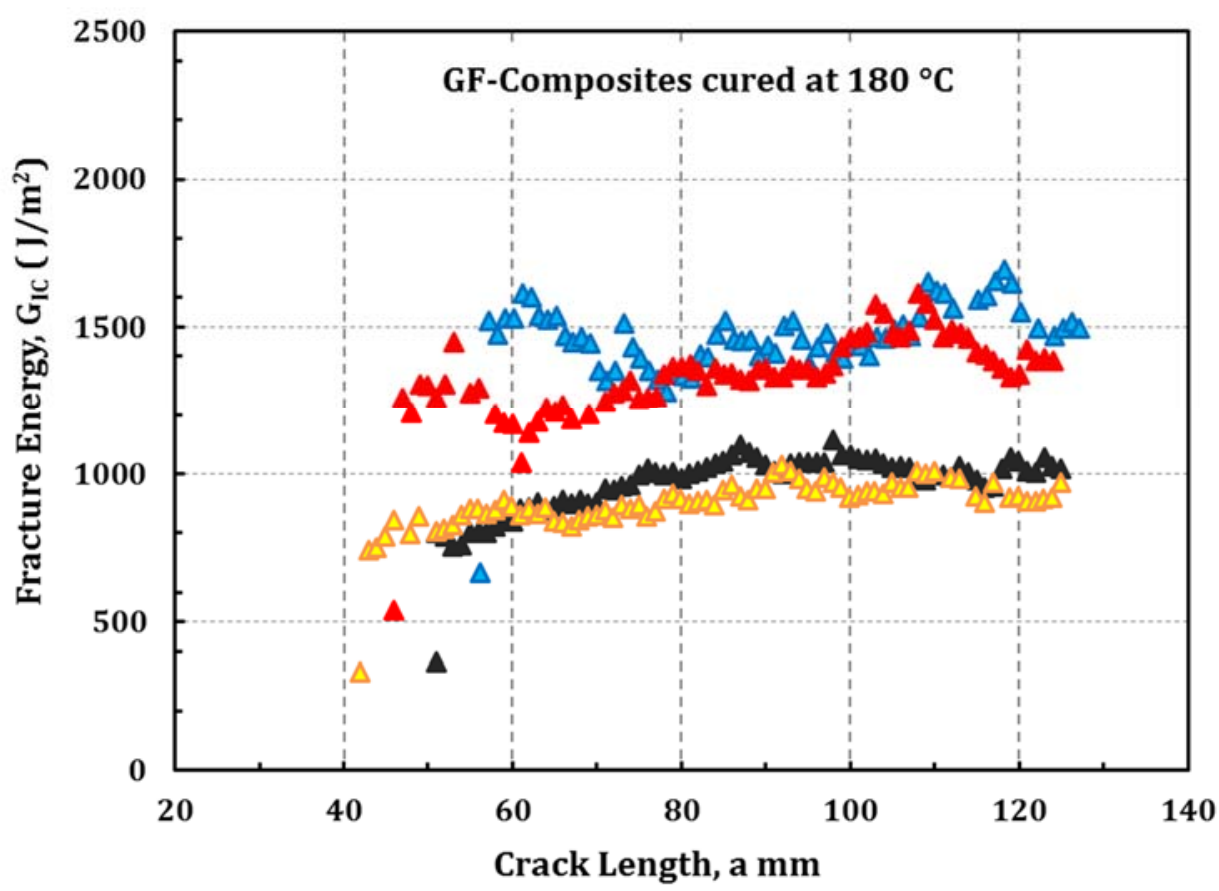

Figure 3 : Typical R-curves from quasi-static DCB tests for GF composites cured at (a) $120^{\circ} \mathrm{C}$, and (b) $180{ }^{\circ} \mathrm{C}$ 

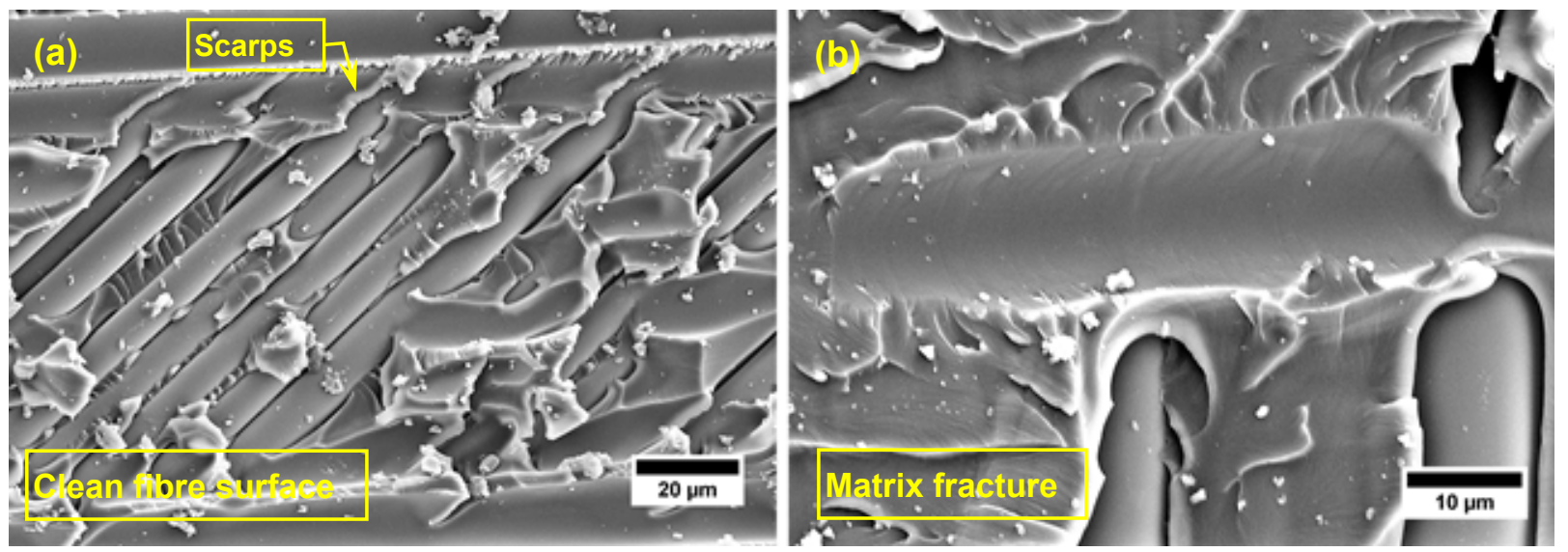

Figure 4 : Quasi-static matrix fracture surfaces of GF-Control, showing (a) clean fibre surfaces and (b) matrix fracture.
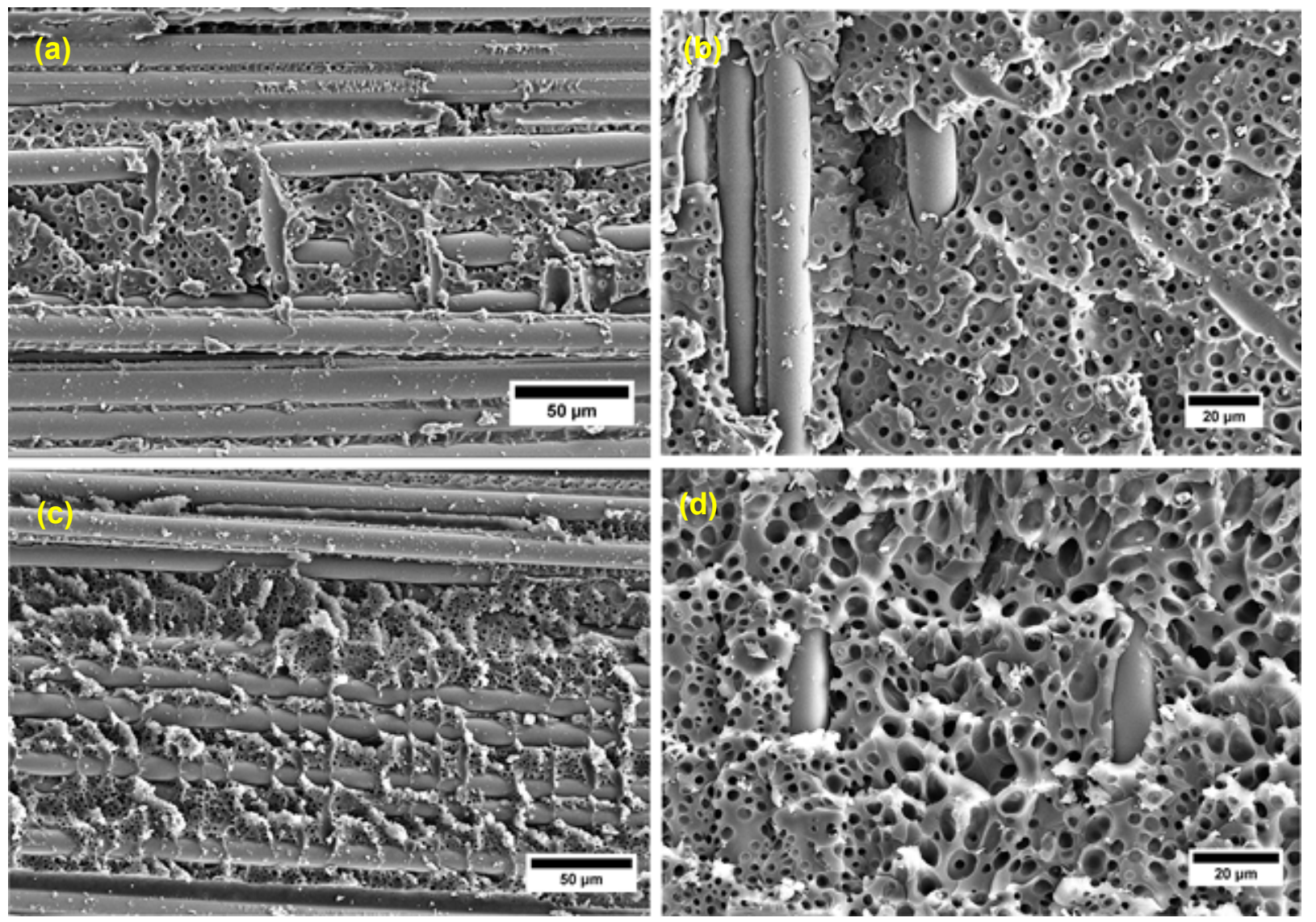

Figure 5 : Quasi-static matrix fracture surfaces of GF-Rubber, (a) and (b) cured at $180^{\circ} \mathrm{C}$, (c) and (d) cured at $120^{\circ} \mathrm{C}$. 

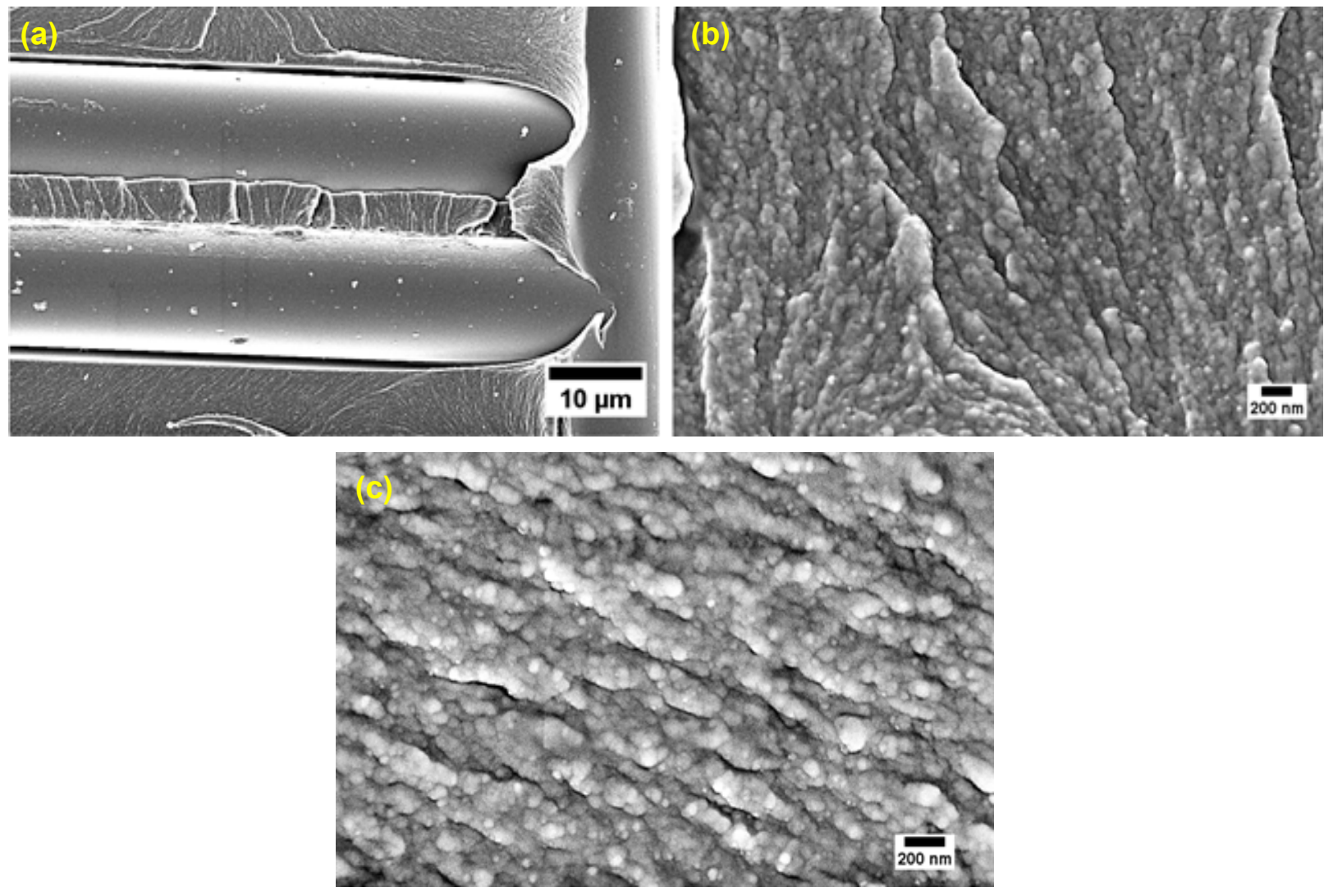

Figure 6 : Quasi-static matrix fracture surfaces of GF-NS, (a) and (b) cured at $180^{\circ} \mathrm{C}$, and (c) cured at $120^{\circ} \mathrm{C}$.
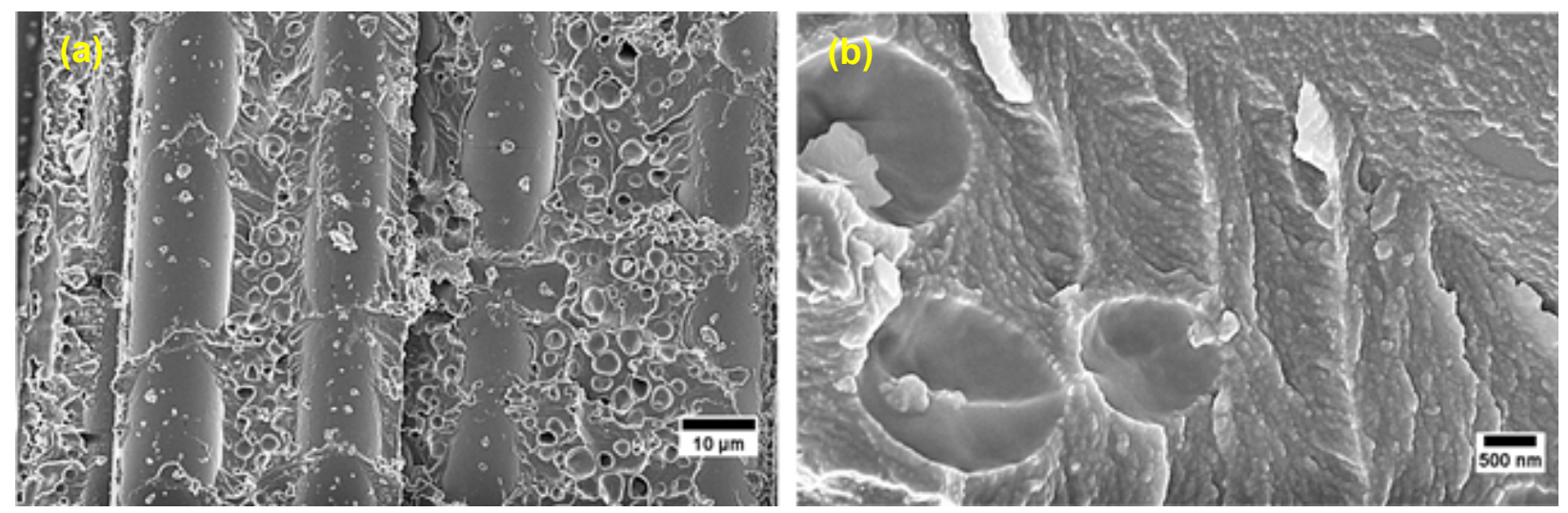

Figure 7 : Quasi-static matrix fracture surfaces of GF-Hybrid, at (a) low magnification, and (b) high magnification. 

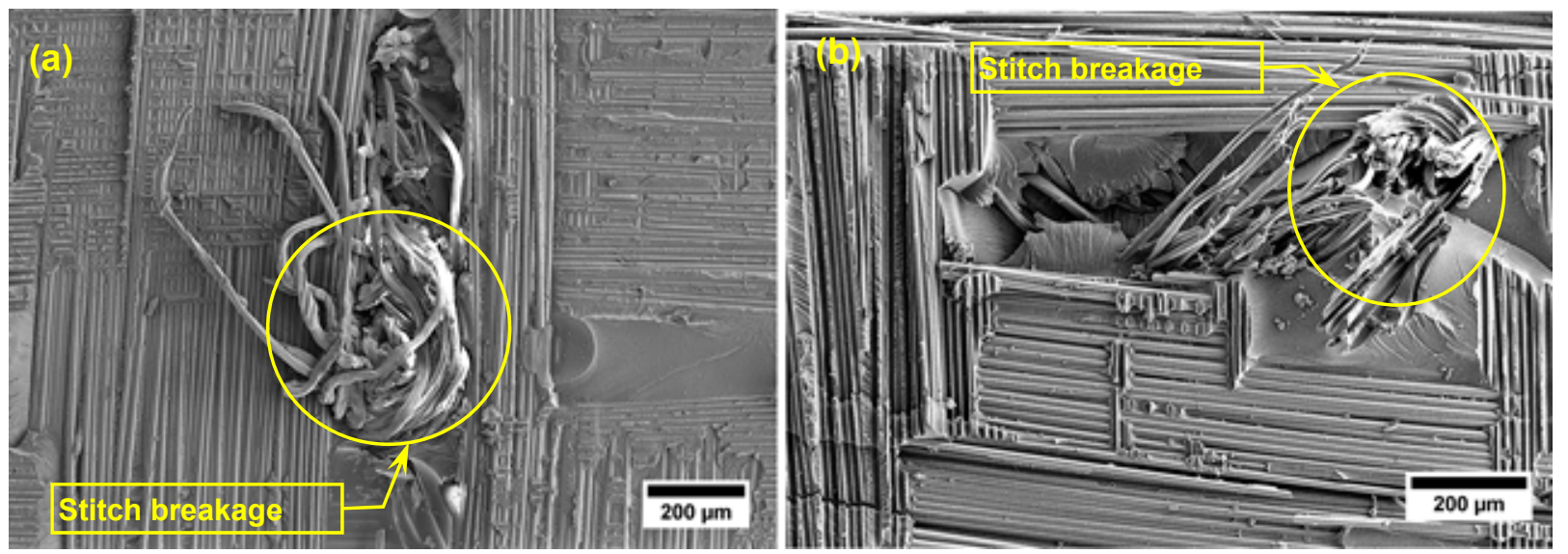

Figure 8 : Fracture surfaces of GF composite specimens showing (a) and (b) stitch tensile breakage.

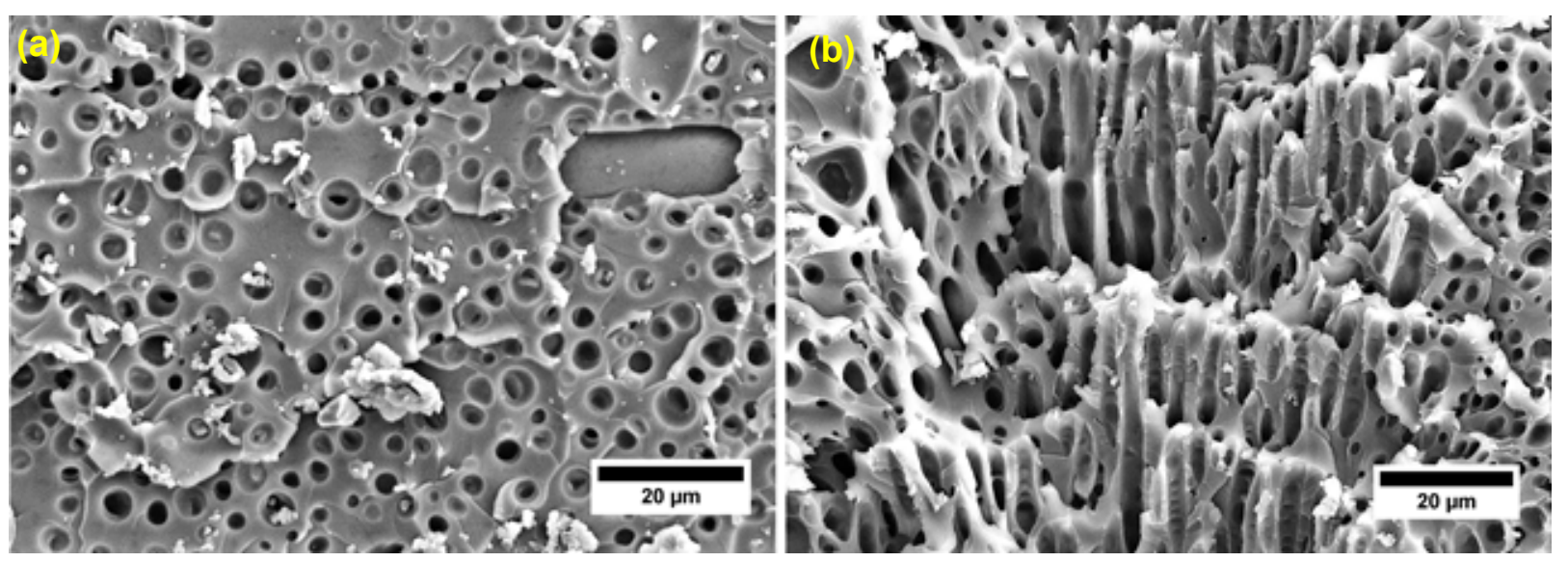

Figure 9 : Comparison of quasi-static matrix fracture surfaces of (a) GF-Rubber cured at $180{ }^{\circ} \mathrm{C}$, and (b) GF-Rubber cured at $120^{\circ} \mathrm{C}$. 

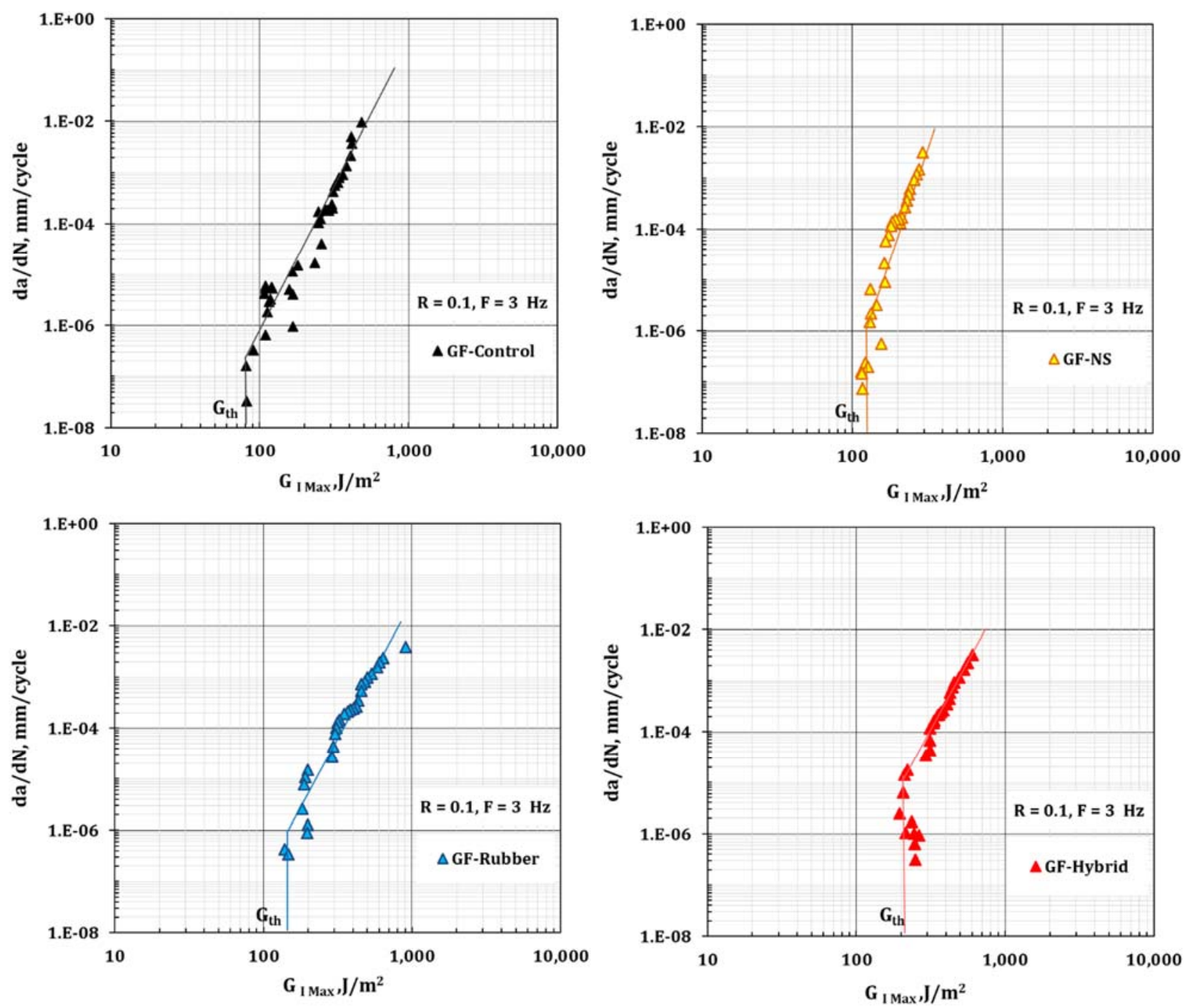

Figure 10 : Fatigue crack growth curves of GF composites with toughened matrices cured at 180 ${ }^{\circ} \mathrm{C}$. Comparison of fatigue threshold for (a) GF-Control, (b) GF-NS, (c) GF-Rubber, and (d) GFHybrid. 

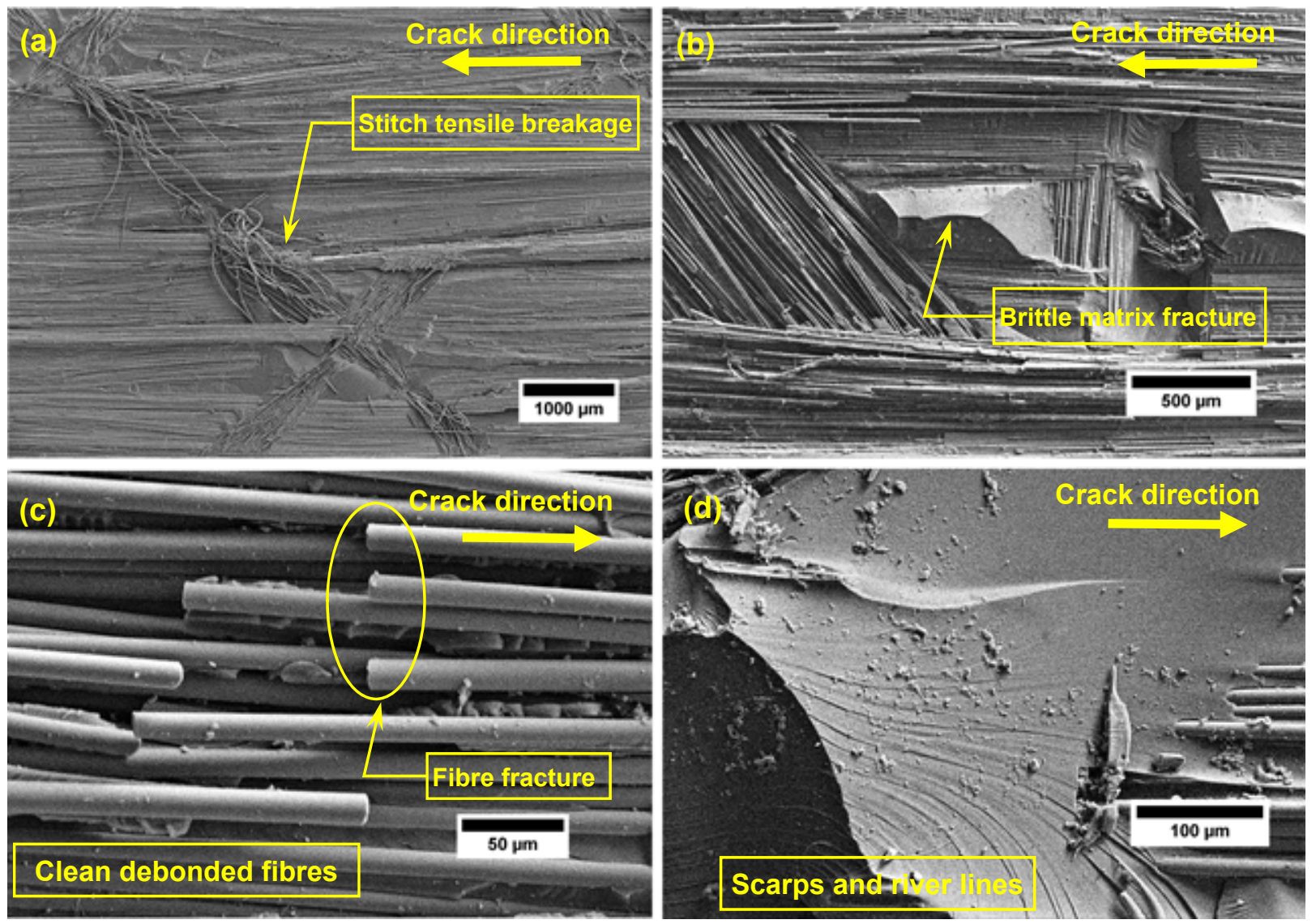

Figure 11 : Fatigue fracture surfaces of GF-Control showing (a) stitch tensile breakage, (b) brittle matrix fracture, (c) clean debonded fibres and fibre fracture, and (d) matrix fracture showing scarps and riverlines 

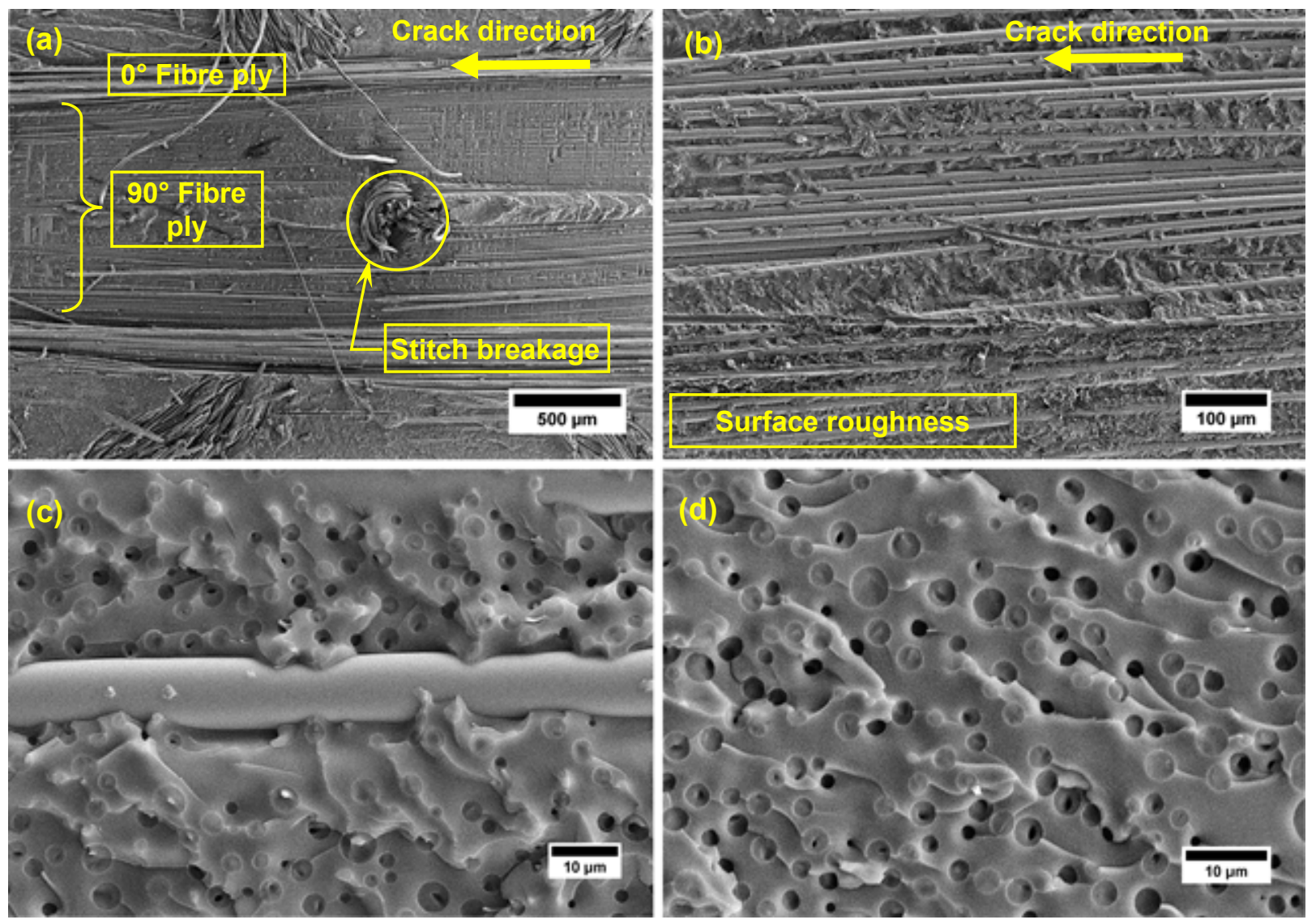

Figure 12 : Fatigue fracture surfaces of GF-Rubber showing (a) fracture at $0^{\circ} / 90^{\circ}$ ply interface with stitch breakage, (b) fibre-matrix adhesion contributing to surface roughness, (c) fibre-matrix adhesion at high magnification, and (d) cavitation of rubber particles at matrix region
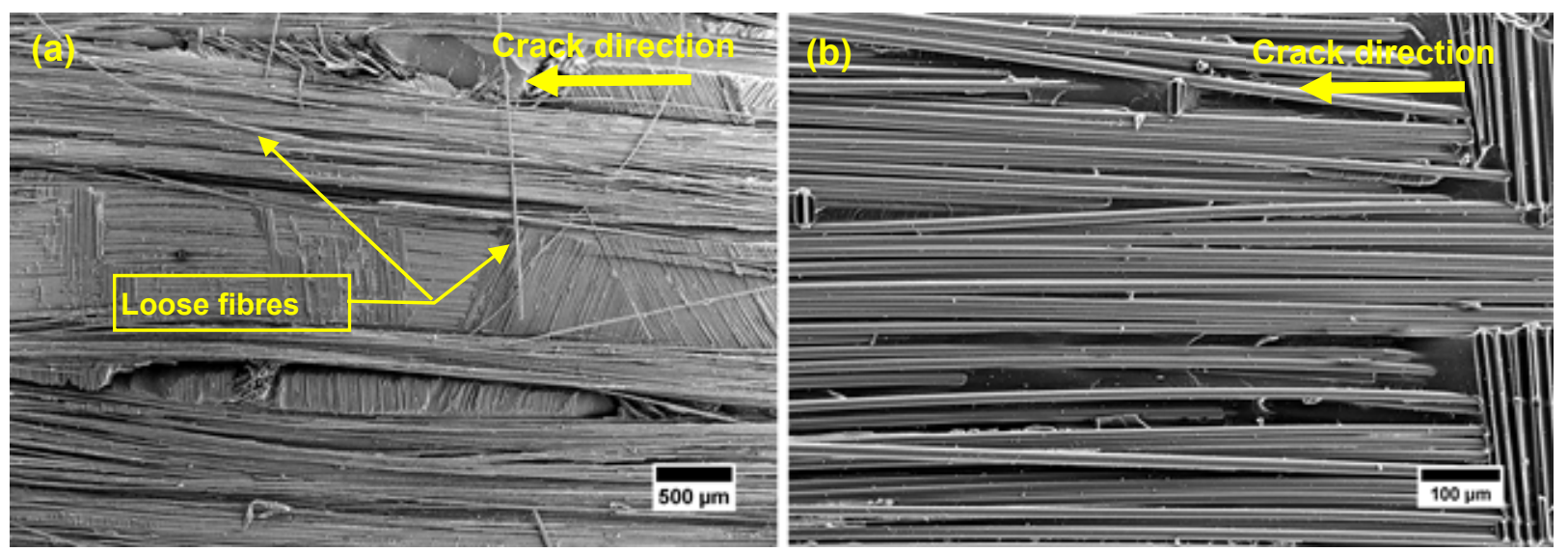

Figure 13 : Fatigue fracture surfaces of GF-NS showing (a) loose fibres on fracture surface at low magnification, and (b) clean debonded fibres on fracture surface at high magnification. 

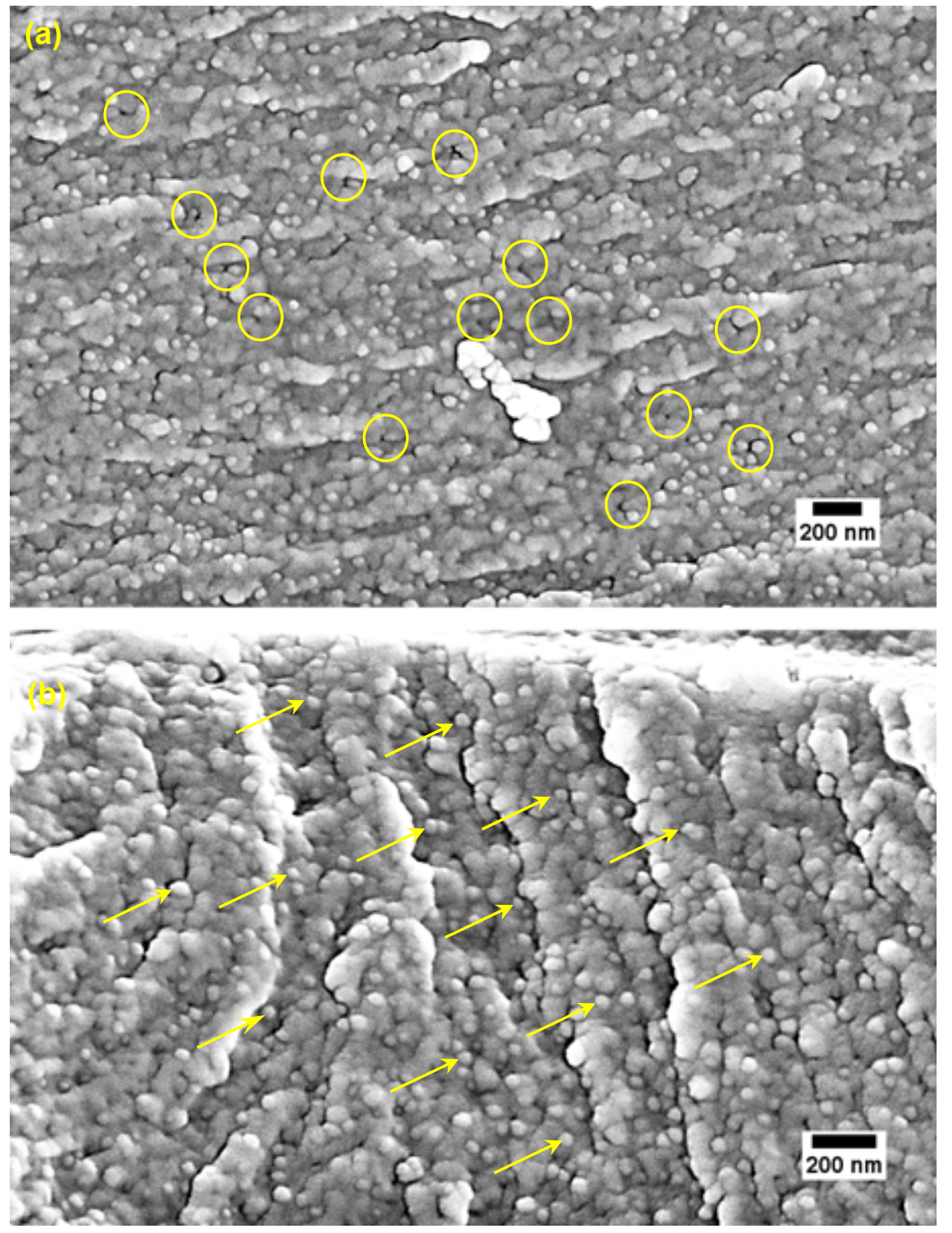

Figure 14 : Matrix fracture of GF-NS under fatigue loading showing (a) voids (as circled) from debonded silica nanoparticles, and (b) debonded silica nanoparticles (indicated with arrows).

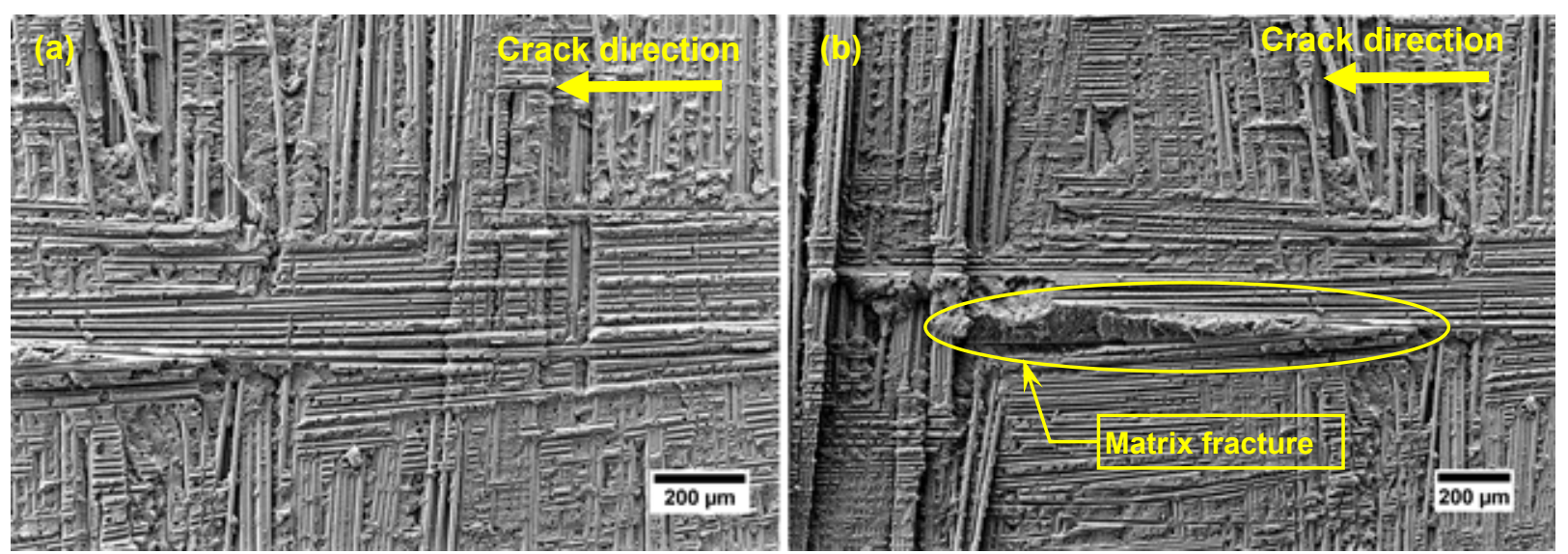

Figure 15 : Fatigue fracture surfaces of GF-Hybrid showing (a) good fibre-matrix adhesion contributing to high surface roughness, and (b) matrix fracture. 

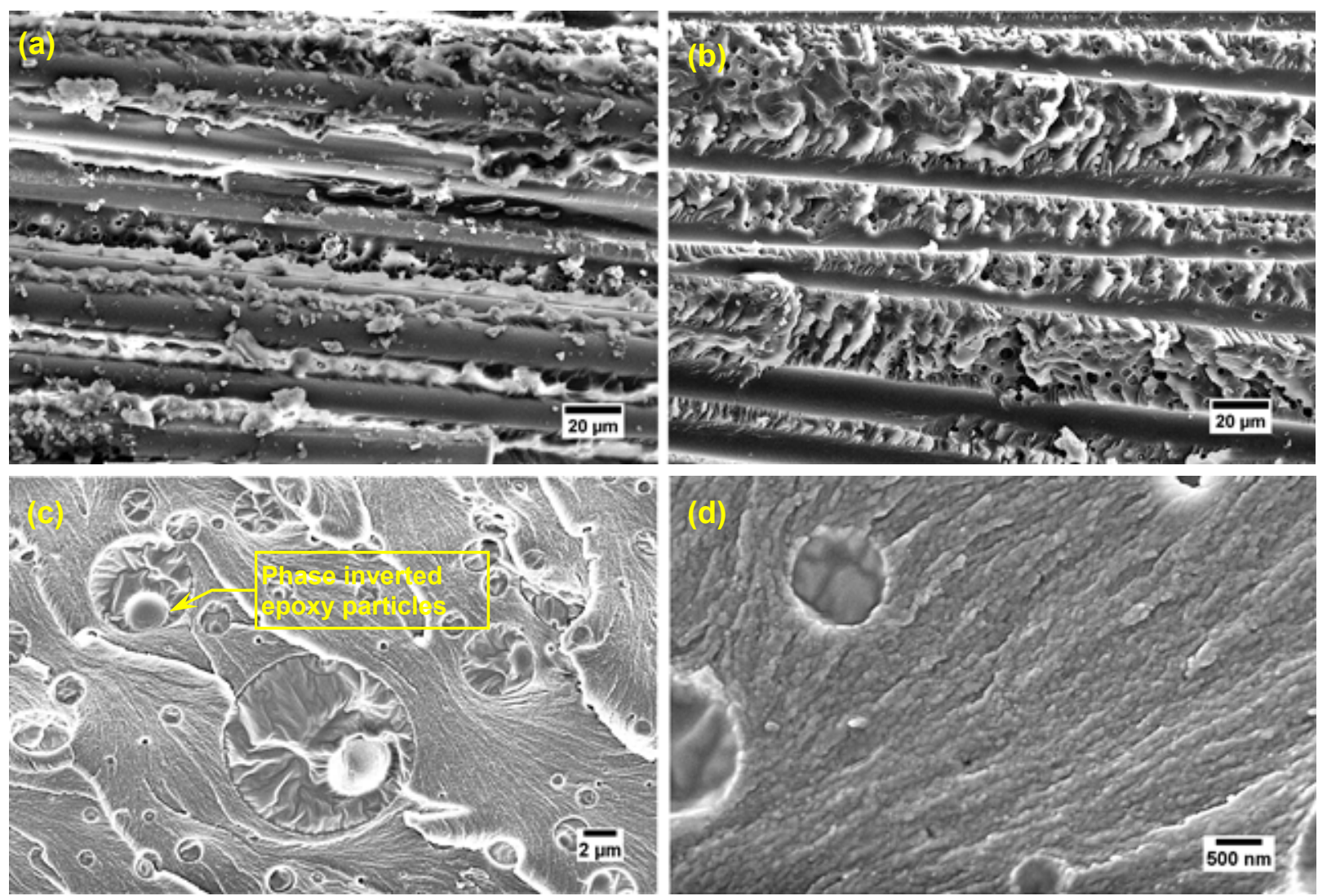

Figure 16 : Matrix fracture of GF-Hybrid under fatigue loading showing (a) good fibre-matrix adhesion indicated by residual epoxy adhered to fibres, (b) extensive matrix deformation under low magnification, (c) local phase inversion of epoxy and cavitation of rubber particles, and (d) rubber particle cavitation with silica nanoparticle-modified matrix surrounding.

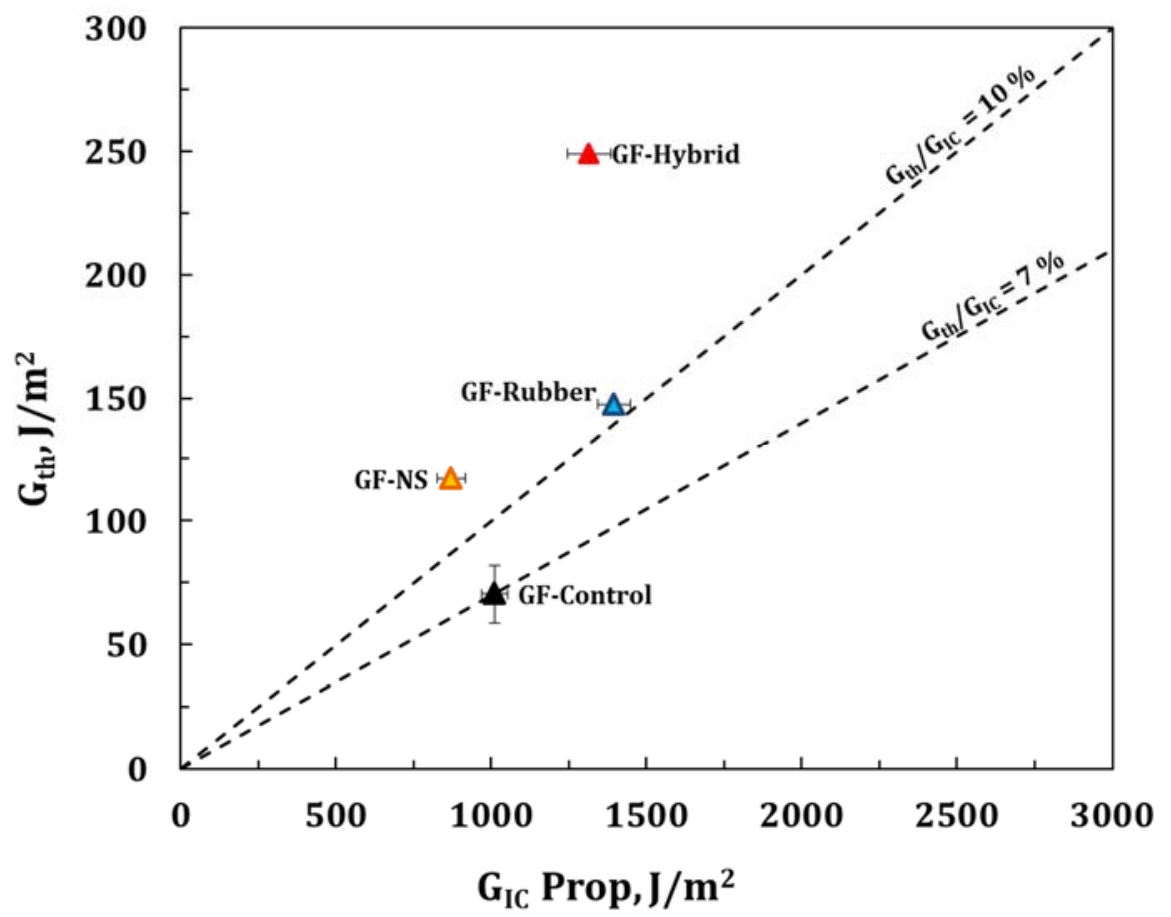

Figure 17: Fatigue threshold versus quasi-static mode I propagation fracture energies of GF composites cured at $180^{\circ} \mathrm{C}$. 
Table 1 : Glass transition temperature, $T_{g}$, values for GF composites and corresponding bulk polymers [50] at different curing temperatures.

\begin{tabular}{|c|c|c|c|c|c|c|c|c|}
\hline \multirow{2}{*}{$\begin{array}{c}\text { GF } \\
\text { Composite } \\
\text { Formulation }\end{array}$} & \multicolumn{4}{|c|}{ Cured at $120^{\circ} \mathrm{C}$} & \multicolumn{4}{|c|}{ Cured at $180^{\circ} \mathrm{C}$} \\
\hline & $\begin{array}{c}\mathrm{T}_{\mathrm{g}} \text { Onset } \\
\left({ }^{\circ} \mathrm{C}\right)\end{array}$ & $\begin{array}{c}\text { Tg Peak } \\
\left({ }^{\circ} \mathrm{C}\right)\end{array}$ & $\begin{array}{c}\mathrm{T}_{\mathrm{g}} \text { Rubber } \\
\left({ }^{\circ} \mathrm{C}\right)\end{array}$ & $\begin{array}{l}\text { Bulk } T_{g} \\
\left({ }^{\circ} \mathrm{C}\right)\end{array}$ & $\begin{array}{c}\mathrm{T}_{\mathrm{g}} \text { Onset } \\
\left({ }^{\circ} \mathrm{C}\right)\end{array}$ & $\begin{array}{c}T_{g} \text { Peak } \\
\left({ }^{\circ} \mathrm{C}\right)\end{array}$ & $\begin{array}{c}\mathrm{T}_{\mathrm{g}} \text { Rubber } \\
\left({ }^{\circ} \mathrm{C}\right)\end{array}$ & $\begin{array}{c}\text { Bulk } T_{g} \\
\left({ }^{\circ} \mathrm{C}\right)\end{array}$ \\
\hline GF-Control & $106 \pm 0.4$ & $116 \pm 0.8$ & - & $128 \pm 2.0$ & $140 \pm 3.4$ & $154 \pm 3.8$ & - & 150 \\
\hline GF-Rubber & $104 \pm 0.0$ & $116 \pm 0.0$ & -50 & $129 \pm 3$ & $134 \pm 0.2$ & $148 \pm 0.3$ & $-51 \pm 1.3$ & 147 \\
\hline GF-NS & $110 \pm 0.8$ & $121 \pm 0.5$ & - & $133 \pm 3$ & $139 \pm 0.0$ & $155 \pm 0.0$ & - & 155 \\
\hline GF-Hybrid & $109 \pm 0.0$ & $122 \pm 0.0$ & $-46 \pm 0.0$ & $133 \pm 3$ & $138 \pm 2.4$ & $155 \pm 1.4$ & $-48 \pm 0.2$ & 155 \\
\hline
\end{tabular}

Table 2 : Fracture energy for GF composites and corresponding bulk polymers [50] at different curing temperatures.

\begin{tabular}{|c|c|c|c|c|c|c|}
\hline \multirow{2}{*}{$\begin{array}{c}\text { GF } \\
\text { Composite } \\
\text { Formulation }\end{array}$} & \multicolumn{3}{|c|}{ Cured at $120^{\circ} \mathrm{C}$} & \multicolumn{3}{|c|}{ Cured at $180^{\circ} \mathrm{C}$} \\
\hline & $\begin{array}{l}G_{I C, \text { Init }} \\
\left(\mathrm{J} / \mathrm{m}^{2}\right) \\
\end{array}$ & $\begin{array}{l}G_{\mathrm{IC}, \text { Prop }} \\
\left(\mathrm{J} / \mathrm{m}^{2}\right) \\
\end{array}$ & $\begin{array}{c}\text { Gc Bulk } \\
\left(\mathrm{J} / \mathrm{m}^{2}\right) \\
\end{array}$ & $\begin{array}{l}\mathbf{G}_{\mathrm{IC}, \text {, nit }} \\
\left(\mathrm{J} / \mathrm{m}^{2}\right) \\
\end{array}$ & $\begin{array}{l}\text { Gic,Prop } \\
\left(\mathrm{J} / \mathrm{m}^{2}\right) \\
\end{array}$ & $\begin{array}{c}\text { Gc Bulk } \\
\left(\mathrm{J} / \mathrm{m}^{2}\right. \\
\end{array}$ \\
\hline GF-Control & $667 \pm 12$ & $1089 \pm 40$ & $100 \pm 28$ & $387 \pm 14$ & $1010 \pm 42$ & $184 \pm 27$ \\
\hline GF-Rubber & $793 \pm 42$ & $1832 \pm 51$ & $519 \pm 42$ & $598 \pm 63$ & $1395 \pm 51$ & $394 \pm 55$ \\
\hline GF-NS & $564 \pm 43$ & $1309 \pm 65$ & $140 \pm 13$ & $341 \pm 12$ & $871 \pm 45$ & $163 \pm 25$ \\
\hline GF-Hybrid & $642 \pm 21$ & $1654 \pm 83$ & $536 \pm 162$ & $533 \pm 9$ & $1314 \pm 70$ & $310 \pm 32$ \\
\hline
\end{tabular}

Table 3 : Summary of the quasi-static and fatigue fracture properties for GF composites cured at $180^{\circ} \mathrm{C}$.

\begin{tabular}{clccc}
\hline Formulation & $\begin{array}{c}c \\
\mathbf{G} \\
\left(\mathbf{J} / \mathbf{m}^{2}\right)\end{array}$ & $\begin{array}{c}\mathbf{G}_{\mathrm{th}} \\
\left(\mathbf{J} / \mathbf{m}^{2}\right)\end{array}$ & $\mathbf{G}_{\mathrm{th}} / \mathbf{G}_{\mathrm{Ic}, \text { Prop }}$ & $\begin{array}{c}\text { Relative } \\
\text { threshold }\end{array}$ \\
\hline \hline GF-Control & $\begin{array}{l}\text { Init : } 387 \pm 14 \\
\text { Prop : } 1010 \pm 42\end{array}$ & 70 & 0.07 & 1.0 \\
\hline GF-Rubber & $\begin{array}{l}\text { Init : } 598 \pm 63 \\
\text { Prop : } 1395 \pm 51\end{array}$ & 148 & 0.11 & 2.1 \\
\hline GF-NS & $\begin{array}{l}\text { Init : } 341 \pm 12 \\
\text { Prop : } 871 \pm 45\end{array}$ & 117 & 0.13 & 1.7 \\
\hline GF-Hybrid & $\begin{array}{l}\text { Init : } 533 \pm 9 \\
\text { Prop : } 1314 \pm 70\end{array}$ & 249 & 0.19 & 3.5 \\
\hline
\end{tabular}


Table 4 : Radius of the plastic zone in the propagation region during quasi-static testing and at the fatigue threshold

\begin{tabular}{|c|c|c|c|}
\hline \multirow{2}{*}{ Formulation } & \multicolumn{2}{|c|}{$\begin{array}{c}\text { Propagation } r_{y} \\
(\mu \mathrm{m})\end{array}$} & \multirow{2}{*}{$\begin{array}{c}\text { Threshold } r_{y} \\
(\mu \mathrm{m})\end{array}$} \\
\hline & $120^{\circ} \mathrm{C}$ & $180^{\circ} \mathrm{C}$ & \\
\hline GF-Control & 2.63 & 6.34 & 2.21 \\
\hline GF-Rubber & 17.8 & 15.8 & 5.68 \\
\hline GF-NS & 4.19 & 7.08 & 4.57 \\
\hline GF-Hybrid & 19.4 & 17.3 & 11.6 \\
\hline
\end{tabular}

Table 5: Synergistic toughening effect determination for the GF-Hybrid composites cured at $180^{\circ} \mathrm{C}$.

\begin{tabular}{cccc}
\hline \multirow{2}{*}{ Formulation } & \multicolumn{3}{c}{ Fatigue Threshold for GF Composites $\left(\mathrm{J} / \mathrm{m}^{2}\right)$} \\
\cline { 2 - 4 } & $\mathbf{G}_{\mathrm{th}}$ & $\Delta \mathbf{G}_{\mathrm{th}}$ & $\begin{array}{r}\text { Additive } \mathbf{G}_{\mathrm{th}} \\
\text { (Equation 7) }\end{array}$ \\
\hline \hline GF-Control & 70 & - & - \\
\hline GF-Rubber & 148 & 78 & - \\
GF-NS & 117 & 47 & - \\
GF-Hybrid & 249 & 179 & 195 \\
\hline
\end{tabular}

